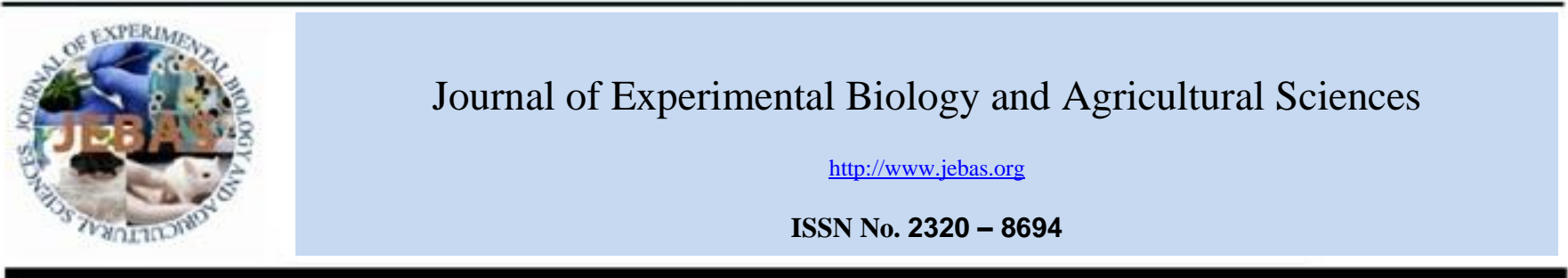

\title{
GREEN SYNTHESIS OF SILVER NANOPARTICLES USING MICROALGAL EXTRACT AND ITS APPLICATION IN METAL ION REMOVAL FROM AQUEOUS SOLUTION
}

\author{
Surindra Negi ${ }^{1 *}$, Vir Singh ${ }^{1}$, Jyoti Rawat ${ }^{2}$ \\ ${ }^{1}$ Department of Environmental Science, G.B. Pant University of Agriculture and Technology, Pantnagar (U.S. Nagar), Uttarakhand, India \\ ${ }^{2}$ Department of Biotechnology, Sir J C Bose Technical Campus Bhimtal, Kumaon University, Bhimtal (Nainital), Uttarakhand, India
}

Received - January 16, 2021; Revision - April 13, 2021; Accepted - April 19, 2021

Available Online - April 25, 2021

DOI: http://dx.doi.org/10.18006/2021.9(2).214.230

KEYWORDS
Algae
Bioreduction
Nanotechnology
Reducing agent
Silver nanoparticles

\begin{abstract}
Heavy metal pollution is of great concern and cannot be ignored as heavy metals are highly mobile in soil and are recalcitrant. Nanotechnology provides a novel sustainable approach for synthesizing materials of desired properties, composition, and structure, it is however expected to adsorb heavy metals and play a significant role in water treatment. Green chemistry is the cost-effective, non-toxic, and environment friendly approach that involves the use of biological components as reducing and stabilizing agents for the synthesis of nanoparticles. In the present study, heavy metals such as cadmium (Cd II) and lead ( $\mathrm{Pb}$ II) were successfully removed from its aqueous solution by an adsorption process using the silver nanoparticles of size $\sim 15 \mathrm{~nm}$ biosynthesized using freshwater algal extract. The adsorption peak at $411 \mathrm{~nm}$ confirms the formation of silver nanoparticles. The maximum value of metal ion adsorption capacity ( $23.98 \mathrm{mg} / \mathrm{g}$ ) was observed for $\mathrm{Pb}$ (II). The higher value of $\mathrm{R}^{2}$ showed that the experimental data were fitted best with Langmuir isotherm. The rate kinetics study showed that $\mathrm{Pb}$ (II) adsorption on $\mathrm{Ag}$ nanoparticles followed pseudo-second order kinetics $\left(\mathrm{R}^{2}>0.9\right)$ indicating that $\mathrm{Pb}$ (II) was attached to the nanoparticles surface through electrostatic force of attraction, also referred to as chemisorption whereas $\mathrm{Cd}$ (II) adsorption on $\mathrm{Ag}$ nanoparticles followed pseudo-first order kinetics $\left(\mathrm{R}^{2}>0.8\right)$ indicating physical adsorption between adsorbate and adsorbent.
\end{abstract}

* Corresponding author

E-mail: drsurindranegi@gmail.com (Surindra Negi)

Peer review under responsibility of Journal of Experimental Biology and Agricultural Sciences.

Production and Hosting by Horizon Publisher India [HPI] (http://www.horizonpublisherindia.in/).

All rights reserved.
All the articles published by Journal of Experimental Biology and Agricultural Sciences are licensed under a Creative Commons Attribution-NonCommercial 4.0 International License Based on a work at www.jebas.org.

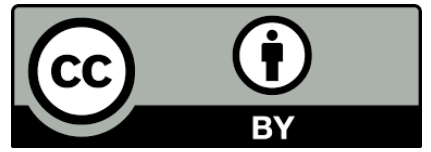




\section{Introduction}

Recent Advancement in nanotechnology has enabled researchers to further explore the unique physical and chemical properties of the nanomaterial. This has expanded its application in various domains such as biomedicine, catalysis, energy storage, and sensors (Xu et al., 2020). Nanoparticles can be engineered by methods such physical as irradiation, diffusion, thermal decomposition, and chemical methods such as condensation, reduction, sol-gel method precipitation, laser pyrolosis, chemical reduction method etc. (Sandhu et al., 2019). However, the use of these methods for the synthesis of nanoparticles are known to impact human health and the environment adversely as it involves the use of hazardous chemicals and releases harmful radiations. In this view, researchers have devised green chemistry as a new approach for the synthesis of nanomaterials that involves the use of biological entities such as plants and microorganism (Mandal et al., 2021). For the synthesis of nanoparticles, bio-components such as cellulose, enzymes, exopolysaccharide, flavonoids, alkaloids, terpenoids, alcohol etc. are responsible for the bio-reduction of metal salt to its elemental form (Xu et al., 2020). The microorganism mediated synthesis of nanoparticles offers particles of smaller size, high surface area to volume ratio, thermal, magnetic, catalytic, and biological properties which pave the way to synthesize different metal and metal oxide nanoparticles successfully (Sandhu et al., 2019). However, the potential contribution of different macromolecules in the formation of nanoparticles is still not known (Karthik et al., 2020).

Furthermore, various nanoparticles namely metal nanoparticles, carbon-based nanoparticles, ceramic nanoparticles, semi-conductor nanoparticles, polymeric, and lipid based nanoparticles have been engineered and are available in different compositions, shapes, sizes, morphologies, chemical, and physical properties. Among different types of noted nanoparticles, metal nanoparticles have drawn a considerable amount of attention due to their exceptional properties including, optical properties, magnetic properties, mechanical strengths, high surface area, high ordered structure, and thermal strength (Abegunde et al., 2020). The kinetics of metal nanoparticles such as silver nanoparticles (AgNPs) is slower, and better manipulation is achieved by crystal growth and stabilization, hence nanoparticles of desired shape and size can be obtained for their wide application for different purposes (Dağlığlu \& Öztürk, 2019).

Recently, various treatment technologies such as photo-Fenton processes, chemical coagulation/flocculation, have been adopted for the removal of pollutants from water and wastewater (Khalid et al., 2017), chemical precipitation (Zhang \& Duan, 2020), nanofiltration (Zhao et al., 2021), ultra-filtration (Yousefi et al., 2021), and ion exchange (Goyal et al., 2021). However, factors such as high operational cost, rigorous use of chemicals, and poor sludge disposal and management limit the use of technology. The adsorption method has been observed as the most useful and effective technique for water and wastewater treatment technique due to its distinctive characteristics such as large surface area, highly porous material, moderate mechanical strength, chemical interaction, and suitable surface charges. Adsorbents such as impregnated biomaterials, synthetic resins, alumina, silica gel, zeolites, activated carbons, and nanoparticles have been commercially used for water and wastewater treatment.

Microalgae are well known for tremendous rapid growth and double their biomass around 10 times quicker than higher plants (El-Sheekh \& El-Kassas, 2016). In general, algae are divided taxonomically into diverse groups such as, Phaeophyta, Chrysophyta, Bacillariophyta, , Rhodophyta, Chlorophyta, Cyanophyta and Dinophyta; and containing essential biomolecules such as antioxidants, polysaccharides, carotenoids, pigments, amino acids, proteins, minerals, lipids, phytohormones, immune stimulators as well as vitamins (El-Sheekh et al., 2020) that plays a major role in reduction and accumulation of molecules. Therefore, in the present study, we aimed to examine the potential of freshwater microalgae Tetradesmus sp. to produce silver nanoparticles and to determine the efficiency of synthesized silver nanoparticles in adsorption of $\mathrm{Pb}$ (II) and Cd (II) metal ions from its aqueous solution.

\section{Materials and methods}

\subsection{Chemicals and reagents}

All the chemicals and reagents used in the present study were of analytical grade.

\subsection{Phycosynthesis of AgNPs}

Patel et al. (2015) methodology was adopted with slight modifications for the biosynthesis of $\mathrm{Ag}$ nanoparticles using microalgae. The freshwater microalgae sample was collected from freshwater lake during the summer season. The collected strains were isolated from the freshwater sample by serial dilution method and were cultivated in BG11 medium. 100 $\mu$ l of the freshwater sample was spreaded on agar plates and was incubated for 5- 10 days at $28 \pm 1{ }^{\circ} \mathrm{C}$ at 3000 lux light intensity and $16: 8 \mathrm{hr}$ light and dark cycle to isolate pure colonies. The growth of microalgae was observed within 2 weeks subsequently three different colonies were picked up. The streak plate method was used to obtain pure colonies of microalgae and then single colony was further transferred in afresh medium (BG-11 broth) at temperature $28 \pm 1^{\circ} \mathrm{C}$ to maintain the purity of the culture. The flask containing microalgal inoculum was illuminated with 3000-4000 lux light intensity and L: D cycles of 16:8 hrs. Proper aeration was provided throughout the growth period. The morphological identification of 
isolated microalgal strain was carried out microscopically and identify by the taxonomic key given by Prescott (1978). The selected isolate was outsourced to determine the microalgal strain at the molecular level. Microalgae were harvested on the 14th day of their growth period and centrifuged at $5000 \mathrm{rpm}$ for $10 \mathrm{~min}$. Pellets were removed from the supernatant and the former was repeatedly washed with distilled water to remove the traces of culture media. Crude extract of algae was prepared using water as an aqueous medium as it is one of the highly polar solvent. The pure microalgal pellets were dried at room temperature $\left(28 \pm 1^{\circ} \mathrm{C}\right)$ and were crushed to obtain a fine powder. For the extraction process, $1.0 \mathrm{~g}$ of dried biomass powder was mixed with $100 \mathrm{ml}$ distilled water and heated at $60^{\circ} \mathrm{C}$ for 25 min using a hot plate with magnetic stirrer. The mixture was allowed to stand at room temperature for cooling; subsequently, filtration was done using 0.2 -micron pore size filter and the resultant extract was stored in the refrigerator at $4^{\circ} \mathrm{C}$ for further use. For the biosynthesis of AgNPs $1 \mathrm{mM}$ of silver nitrate (AgNO3) was used as a precursor agent. The aqueous extract was added drop-wise to $80 \mathrm{ml}$ of $1 \mathrm{mM}$ AgNO3 solution till the colorless solution turned into brown color, also the solution was shaken well to ensure the complete mixing of the components. The total volume of extract utilized was found to be $16.5 \mathrm{ml}$; double distilled water was added to make up the volume to $100 \mathrm{ml}$. The mixture was kept in dark to prevent the photoactivation of $\mathrm{AgNO} 3.1 \mathrm{mM} \mathrm{AgNO} 3^{+}$. Aqueous extract of microalgae were mixed homogeneously and reduction of $\mathrm{Ag}+$ to Capped zerovalent $\mathrm{Ag}\left(\mathrm{Ag}^{0}\right)$ was carried out followed by Spray drying of colloidal solution of nanoparticles.

\subsection{Characterization of biosynthesized nanoparticles}

High resolution SEM analysis (JEOL, JSM-6490LA) of synthesized nanoparticles was carried out at an accelerating voltage of $20 \mathrm{KV}$. The samples were dried for $24 \mathrm{hrs}$ to remove moisture content. The powdered samples were placed in the grid and the high quality images were obtained at different resolutions. A powerful analytical system transmission electron microscopy of JEOL, 2100F model was used to identify the shapes and sizes of the biosynthesized nanoparticles. TEM images were used to determine the size of the nanoparticles with the help of image $\mathbf{J}$ software. Nanoparticles were selected randomly to create a Gaussian size distribution histogram. The XRD patterns for synthesized nanoparticles were obtained using D8-Advance, Bruker X-ray diffractometer included $\mathrm{Cu} \mathrm{K}$ alpha as a source of radiation (equals to $1.5406 \AA$ ) and LINXEYE XE as a detector. The instrument was operated at a voltage $40 \mathrm{kV}$ with $40 \mathrm{~mA}$ functional current. The powdered NPs samples were placed on the sample holder carefully and were analyzed using a $2 \theta$ range from $20^{\circ}$ to $80^{\circ}$. The obtained patterns were compared with ICDDJCPDS (International Centre for Diffraction Data-Joint Committee of Powder Diffraction Standards) to determine the crystallinity of nanoparticles. The other fractions may be originated due to the presence of impurities of organic components in the samples. In FTIR spectroscopy, a spectra of \% transmission of radiation is obtained when a beam of infrared radiation passes through the sample. In the present study, the Nicolet-6600 FT-IR spectrometer model was used to determine the IR spectra of the samples using wavelength ranged from 400 to $4000 \mathrm{~cm}^{-1}$ with a spectral resolution of $4 \mathrm{~cm}^{-1}$. The powdered samples of nanoparticles and algal pellets were oven dried overnight to eliminate the moisture content and were ground with $\mathrm{KBr}$ before the analysis.

\subsection{Adsorption studies}

The experiment was conducted in batch mode to study the adsorption of $\mathrm{Pb}$ (II) and $\mathrm{Cd}$ (II) on the surface of synthesized $\mathrm{Ag}$ nanoparticles (Ifijen et al., 2020). The influence of contact time, $\mathrm{pH}$, temperature, adsorbate, and adsorbent dose on the adsorption capacity of the nanoparticles was evaluated in the study. The suspensions containing a concentration of individual metal ions were agitated at $150 \mathrm{rpm}$ in a shaker for predetermined period. The samples were centrifuged at $8000 \mathrm{rpm}$ for $30 \mathrm{~min}$ and resulted supernatant was filtered through Whatman 42 filter paper for the estimation of heavy metal concentration. All the experiments were conducted in triplicate and average values were taken into consideration. The \% removal of the heavy metal ion from the solution was calculated using the simple expression as given below (Al-Qahtani, 2017):

$$
\% \text { Removal }=\frac{C_{o}-C_{f}}{C_{o}} \times 100
$$

where $\mathrm{C}_{\mathrm{o}}(\mathrm{mg} / \mathrm{l})$ and $\mathrm{C}_{f}(\mathrm{mg} / \mathrm{l})$ are the initial and final concentrations of the metal ion in the solution respectively.

Salts of $\mathrm{CdCl}_{2}$ and $\mathrm{PbCl}_{2}$ were dissolved in distilled water to prepare $1000 \mathrm{mg} \mathrm{L}^{-1}$ stock solutions. The different concentrations required to study the adsorption process were prepared using stock solutions (Ge et al., 2012).

\subsection{Batch mode adsorption experiment}

The experiments were conducted in batch mode to determine the effects of various factors on the heavy metal removal efficiency of nanoadsorbents (Chandra \& Khan, 2020). For the experiment, 0.5 $\mathrm{g} / \mathrm{L}$ of nanoadsorbent was mixed with heavy metal solution (100 $\mathrm{ml}$ of $100 \mathrm{mg} / \mathrm{l})$ and was shaken at $150 \mathrm{rpm}$ in an orbital shaker for different time of contact: 5, 10, 30, 50, 70, 90, 120, 140 and 180 minutes. On no account adjustment in the $\mathrm{pH}$ and temperature of the solution was done for the adsorption study. The concentration of hydrogen ions in the solution affects the adsorption process. Therefore to study the effect of $\mathrm{pH}$ on the removal efficiency of an adsorbent varying range of $\mathrm{pH}$ was selected: $2,4,6,8$, and 10 . The 
desired $\mathrm{pH}$ of the reaction mixture (adsorbate: 100mg/L; adsorbent: $0.5 \mathrm{~g} / \mathrm{L}$ ) was maintained by $0.1 \mathrm{~N} \mathrm{NaOH}$ and $0.1 \mathrm{~N} \mathrm{HCl}$. The previously determined time of contact was employed in the experiment at room temperature. The concentration of adsorbent plays a significant role in the effective and rapid removal of the pollutants hence optimization of the adsorbent dose is highly preferable. In the experiment, nanoadsorbent of different concentrations i.e. $0.05,0.10,0.20,0.50,0.90 \mathrm{~g} / \mathrm{L}$ was mixed with heavy metal solution $(100 \mathrm{ml}$ of $100 \mathrm{mg} / \mathrm{l})$ and was shaken at 150 $\mathrm{rpm}$ in an orbital shaker for the period as identified in the previous experiment. Optimized contact time and $\mathrm{pH}$ were employed in the experiment at room temperature.

To study the effect of initial concentration of heavy metal ions on the adsorption capacity of the nanoparticles varied concentration of the metal solution was chosen for the study i.e. 50, 100, 150 and 200, 250 and $300 \mathrm{mg} / \mathrm{L}$. The previously determined contact time and $\mathrm{pH}$ were employed in the experiment at room temperature. To determine the effect of temperature on adsorption, the batch experiment was conducted at different temperature $(5,20,35,50$, 65 , and $\left.80^{\circ} \mathrm{C}\right)$, initial metal ion concentration $(100 \mathrm{mg} / \mathrm{L})$, adsorbent dose $(0.5 \mathrm{~g} / \mathrm{L})$ contact time $(120 \mathrm{~min})$ and $\mathrm{pH}$ (as determined in the above experiments).

After performing each above mentioned experiment the samples were centrifuged (at $8000 \mathrm{rpm}$ for 30 minutes) and the supernatant was used to determine the heavy metal concentration by AAS analytical technique (Sens-AA, GBC- Scientific equipment). The sorption efficiency of nanoparticles can be calculated using the following equation (Ali et al., 2018):

$$
q_{e}=\frac{C_{o}-C_{e}}{\mathrm{M}} \times \mathrm{V}
$$

where, qe is the concentration of adsorbed metal ion onto the nanoparticles at equilibrium in $\mathrm{mg} / \mathrm{g}, \mathrm{C}_{o}$ and $\mathrm{C}_{e}$ are initial and equilibrium concentration of metal ions in $\mathrm{mg} / \mathrm{l}, \mathrm{V}$ is the volume of the reaction mixture in Liters and $\mathrm{M}$ is the concentration of nanoparticles used in the reaction mixture in grams.

\subsection{Adsorption isotherm}

The results obtained from the metal ion removal studies using varied concentrations of heavy metals (adsorbate) were fitted to different models to identify the adsorption capacity of nanoparticles. Langmuir isotherm (Langmuir, 1918) and Freundlich isotherm (Freundlich, 1907) models were fitted to the experimental data obtained from the metal removal study. The empirical equation of the Freundlich isotherm model can be expressed as Freundlich (1907):

$$
\log q_{e}=\log K_{F}+\frac{1}{n} \log C_{e}
$$

where, $\mathrm{K}_{F}$ and $\mathrm{n}$ are the two Freundlich constant that denotes the adsorption capacity of adsorbent $(\mathrm{mg} / \mathrm{g})$ and adsorption intensity (affinity with which adsorbate are attached to adsorbent) respectively; where, $1<\mathrm{n}<10$ shows that adsorption if favourable and $\mathrm{n}<1$ shows that the adsorption is unfavourable (Venkateswarlu et al., 2015). The numerical values of both the constants can be computed by plotting $\ln \mathrm{q}_{\mathrm{e}}$ against $\ln \mathrm{C}_{\mathrm{e}}$.

The Langmuir equation (Langmuir, 1918) is based on the assumption that a finite number of binding sites is distributed homogeneously over the surface of the adsorbent and also that the adsorbate gets attached to the outer surface of the adsorbent forming a single molecular layer. Once the monolayer is formed no further sorption takes place with zero interaction between the adsorbed materials. It can be further described using the equation as given below:

$$
\frac{\mathrm{C}_{\mathrm{e}}}{\mathrm{q}_{\mathrm{e}}}=\frac{\mathrm{C}_{\mathrm{e}}}{\mathrm{q}_{0}}+\frac{1}{\mathrm{q}_{0} \mathrm{~K}_{\mathrm{L}}}
$$

Where, $\mathrm{q}$ is the concentration of adsorbed metal ion onto the nanoparticles at equilibrium in $\mathrm{mg} / \mathrm{g}$; $\mathrm{Ce}$ is the concentration of adsorbed metal ion in the reaction mixture at equilibrium in $\mathrm{mg} / \mathrm{L}$; $\mathrm{q} 0$ is the maximum adsorption capacity of adsorbent $(\mathrm{mg} / \mathrm{g})$; $\mathrm{KL}$ is the Langmuir constant $(\mathrm{L} / \mathrm{mg})$ that reflects the affinity of active binding sites quantitatively.

The parameters $\mathrm{q} 0$ and $\mathrm{KL}$ are determined by plotting $\mathrm{C}_{\mathrm{e}} / \mathrm{q}_{\mathrm{e}}$ against $\mathrm{C}_{\mathrm{e}}$. The equilibrium parameter (RL) is dimensionless constant and classified as one of the key features of the Langmuir isotherm model and can be denoted as:

$$
R_{L}=\frac{1}{1+\left(1+K_{L} C_{i}\right)}
$$

where, $C_{i}$ is the initial concentration of adsorbate and $\mathrm{K}_{\mathrm{L}}$ is the Langmuir constant related to the energy of adsorption.

The resultant value of the equilibrium parameter (RL) determines whether the nature of adsorption is favourable (when $0<R L<1$ ), unfavourable $(R L>1)$, linear $(R L=1)$, or irreversible $(R L=0)$.

\subsection{Rate kinetics}

In the present study, the data obtained from the batch experiment was modelled using simplified kinetic models such as pseudo firstorder and pseudo second-order models to determine the rate of adsorption of heavy metal ions onto the surface of biosynthesized nanoparticles. The batch kinetic experiment was carried out to determine the time at which equilibrium condition prevails in the reaction mixture also termed as equilibrium time. For the adsorption kinetic study, $0.5 \mathrm{~g} / \mathrm{L}$ of nanoparticles was dissolved in $100 \mathrm{mg} / \mathrm{L}$ of metal solution at native $\mathrm{pH}$ and kept on the orbital shaker $(150 \mathrm{rpm})$ for $180 \mathrm{~min}$. The pseudo first-order order 
equation which is used to describe the sorption rate is given as (Lagergren, 1898):

$$
\log \left(\mathrm{q}_{\mathrm{e}}-\mathrm{q}_{\mathrm{t}}\right)=\log \left(\mathrm{q}_{\mathrm{e}}\right)-\frac{\mathrm{K}_{1} \mathrm{t}}{2.303}
$$

where, qe and qt are the amount of metal adsorbed per unit weigh of nanoparticles $(\mathrm{mg} / \mathrm{g})$ at equilibrium and at the time " $\mathrm{t}$ " respectively and $K_{1}$ is the pseudo first-order rate constant in $1 / \mathrm{min}$ which can be determined by plotting $\ln \left(\mathrm{q}_{\mathrm{e}^{-}} \mathrm{q}_{\mathrm{t}}\right)$ against time $\mathrm{t}(\mathrm{min})$

The adsorption rate can be determined by using pseudo-secondorder equation as given below (Ho \& McKay, 2000):

$$
\frac{\mathrm{t}}{\mathrm{q}_{\mathrm{t}}}=\frac{1}{\mathrm{~K}_{2} \mathrm{q}_{\mathrm{e}}^{2}}+\frac{\mathrm{t}}{\mathrm{q}_{\mathrm{e}}}
$$

where, qe and qt are the amount of metal adsorbed per unit weight of nanoparticles $(\mathrm{mg} / \mathrm{g})$ at equilibrium and at time $\mathrm{t}$ respectively and $\mathrm{K}_{2}$ is the pseudo second-order rate constant which can be determined by plotting $\mathrm{t} / \mathrm{q}_{\mathrm{t}}$ against time $\mathrm{t}$.

\section{Results and Discussion}

\subsection{Identification of isolated freshwater microalgal strain}

The isolate was selected on the basis of higher optical density (2.46), biomass concentration (168.4 $\pm 0.22 \mathrm{mg} \mathrm{L}-1$ day-1), and specific growth rate $(1.63 \pm 0.31 \mu \mathrm{g} /$ day $)$. The obtained microscopic view of the selected isolate of microalgal strain (Figure 1) was found similar to type Scenedesmus when compared with algaeBase database (Guiry \& Guiry, 2015). The Scenedesmus cells comprise of a single nucleus and one pyrenoid containing chloroplas (Chaidir et al., 2016). The identification of selected microalga strain was based on an Internal transcribed spacer (ITS) sequence. The $\sim 600 \mathrm{bp}$, ITS fragment was amplified using high-fidelity PCR polymerase. The PCR product was sequenced bi-directionally and the sequence data was aligned and analysed to identify the sample

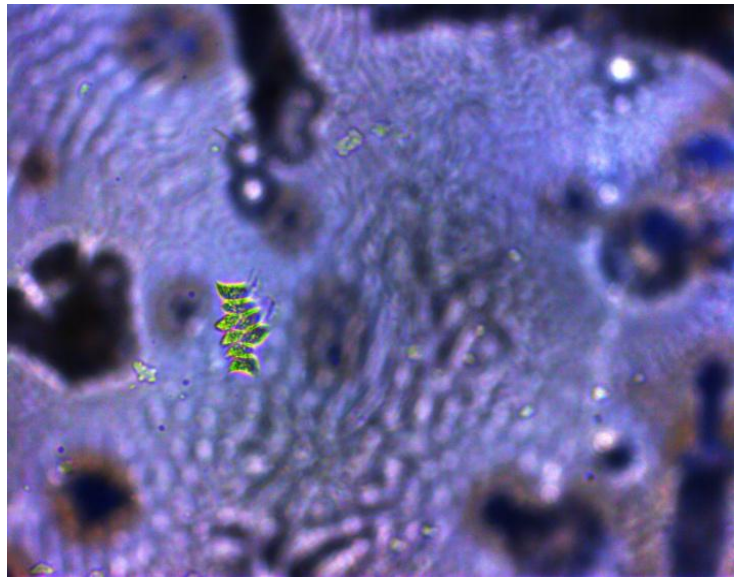

(a) and its closest neighbours. The molecular identification was done to determine the similarity of the species. The microscopic morphological analysis of isolated microalgal strain confirmed that the isolated microalgal strain belongs to the eukaryotic group. Figure 2 shows the developed phylogenetic tree representing the evolutionary relationship among different organisms. The microalgal sample was found to be Tetradesmus dimorphus isolate 959_218S ribosomal RNA gene, partial sequence; internal transcribed spacer 1, 5.8S ribosomal RNA gene, and internal transcribed spacer 2, complete sequence; and 28S ribosomal RNA gene, partial sequence. It was observed that the isolated microalgal strain is clustered with four different strains of Tetradesmus dimorphus with sequence similarities of $99 \%$.

\subsection{Synthesis and characterization of AgNPs}

The colour of the solution changed from bright yellow to dark brown within an hour of the reaction indicating the presence of $\mathrm{Ag}$ nanoparticles (Figure 3). The appearance of silver nanoparticle adsorption peak was periodically monitored at 200-700 nm wavelength range for $1,5,15,20$, and 30 days to assess the stability of phycosynthesized AgNPs. Figure 4 shows the maximum peak of UV-Vis spectra for silver nanoparticles at 411 $\mathrm{nm}$ with increased absorbance due to the increase in the number of nanoparticles with time, indicating the smaller size. The SPR band position is highly influenced by the shape and size of the nanoparticles. Several studies have reported the presence of silver nanoparticles at an absorbance peak ranging from 400-450 nm (Yousaf et al., 2020; Jabir et al., 2021; Aravind et al., 2021). Therefore, the aforementioned observation showed the successful bioreduction of $\mathrm{Ag}$ nanoparticles. The appearance of $\mathrm{UV}-\mathrm{Vis}$ adsorption spectra of nanoparticles is controlled by SPR and represents the shifts in the adsorption peak from red to blue end due to the slight deviations in the shape and size of the nanoparticles (Raghunandan et al., 2011).

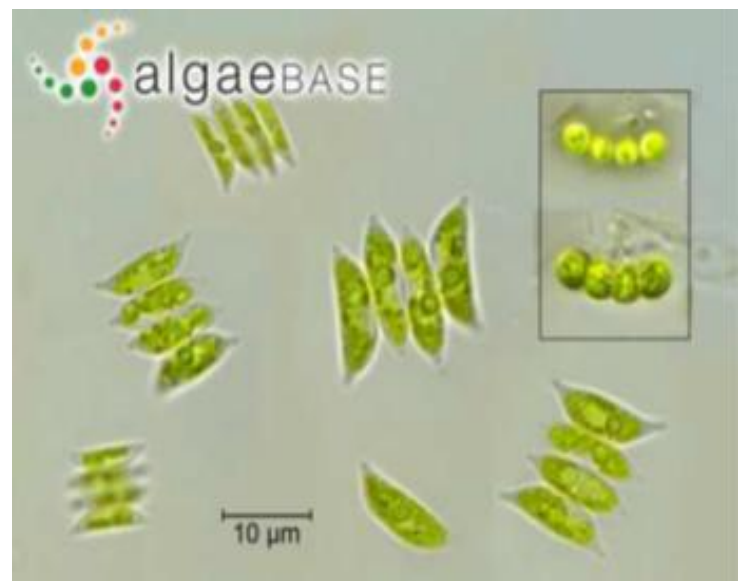

(b)

Figure 1 Identified shape morphology of isolated microalgal strain (a) and Scenedesmus (b) (source: algaebase.org)

Journal of Experimental Biology and Agricultural Sciences http://www.jebas.org 


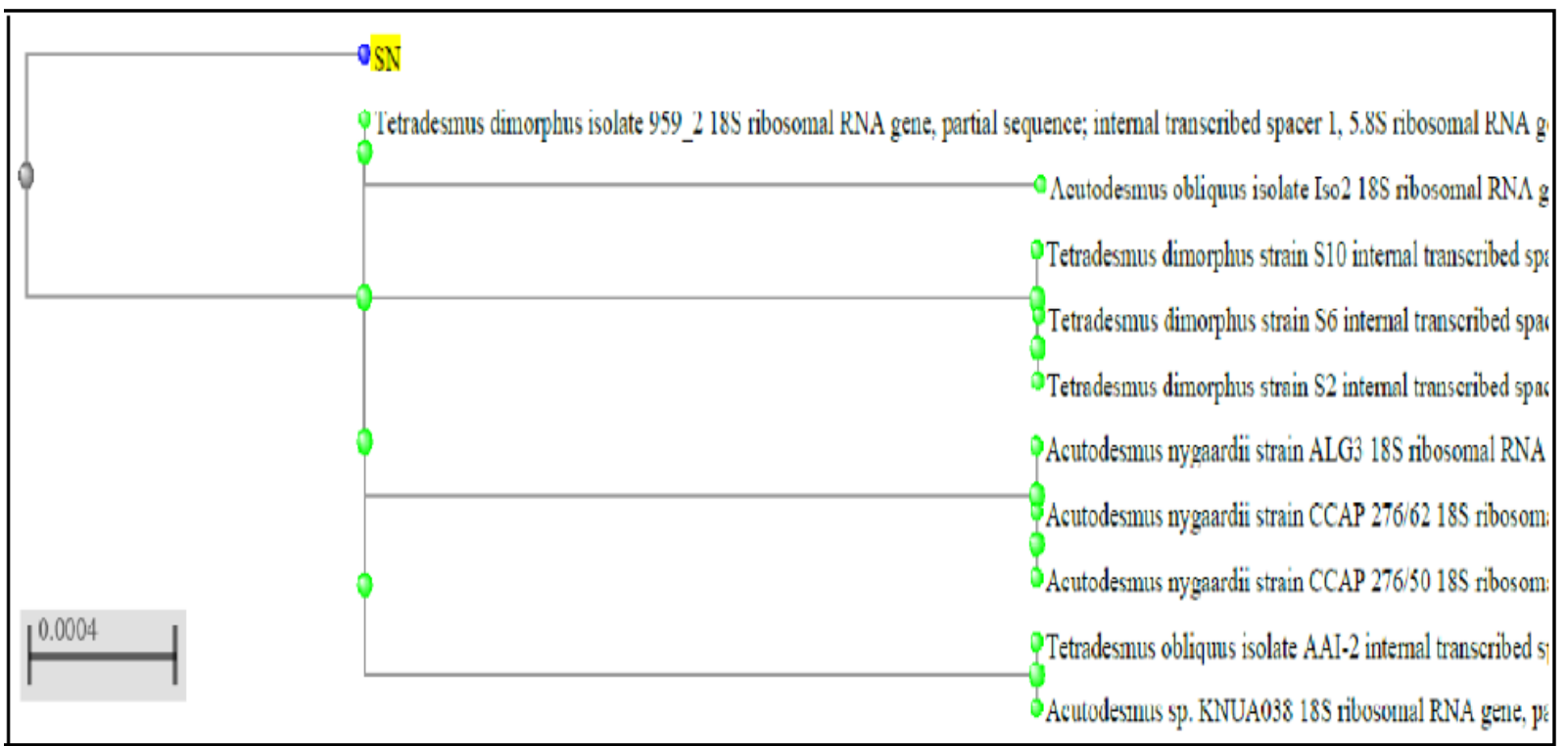

Figure 2 Phylogenetic tree showing evolutionary relatedness of isolated microalgal strain with their closely related microalgae species

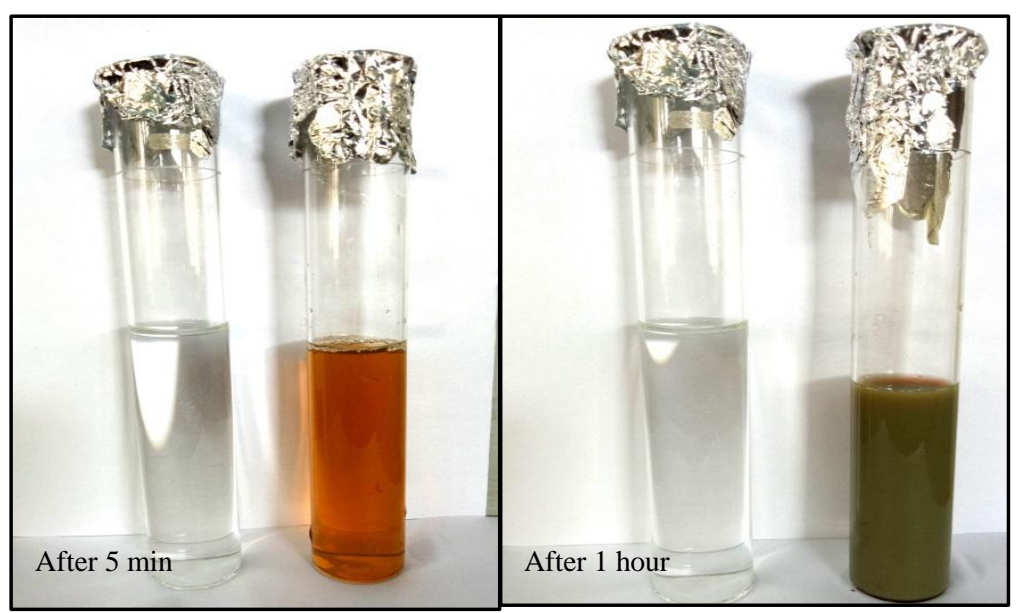

Figure3 Synthesis of nanoparticles $\mathrm{AgNO}_{3}$ and algal extract solution after 5 min and 1 hour.

The obtained XRD pattern for AgNPs is shown in Figure 5. The obtained XRD pattern of Ag nanoparticles showed four distinctive diffraction peaks at 2 theta values of $38.12^{\circ}, 44.06^{\circ}, 64.31^{\circ}$ and $77.58^{\circ}$ which is assigned to the planes (111), (200), (220), and (311) of face centered cubic (fcc) structure of $\mathrm{Ag}$ nanoparticles respectively. The XRD pattern of the current study was matched with the standard database of the Joint Committee on Powder Diffraction Standards (JCPDS card no. 04-0783 and 84- 0713). The observed peak pattern indicated the crystalline nature of biosynthesized and formation of zerovalent $\mathrm{Ag}\left(\mathrm{Ag}^{0}\right)$ nanoparticles.

The SEM images of phycosynthesized AgNPs are presented in Figure 6. It can be seen in the images that the synthesized AgNPs are spherical. The image obtained from SEM imaging displayed agglomeration of larger particles of powdered $\mathrm{Ag}$ nanoparticles. To get a better understanding of the morphology of biologically synthesized nanoparticles and to avoid the imaging of unwanted residue, the colloidal solution of the nanoparticle was washed 3-4 times with deionized water.

The biosynthesized AgNPs using aqueous extract of microalgal species were further analyzed by using TEM which is considered the most powerful and advanced analytical technique in determining the surface morphology of nano-sized particles (Figure 7). The average particle size of Ag nanoparticles were calculated by imageJ software using TEM images from which Gaussian distribution of nanoparticle size was obtained (Figure 8). The average particle sizes of AgNPs were found to be $15 \pm 4.05 \mathrm{~nm}$ and polymorphic in shape. 


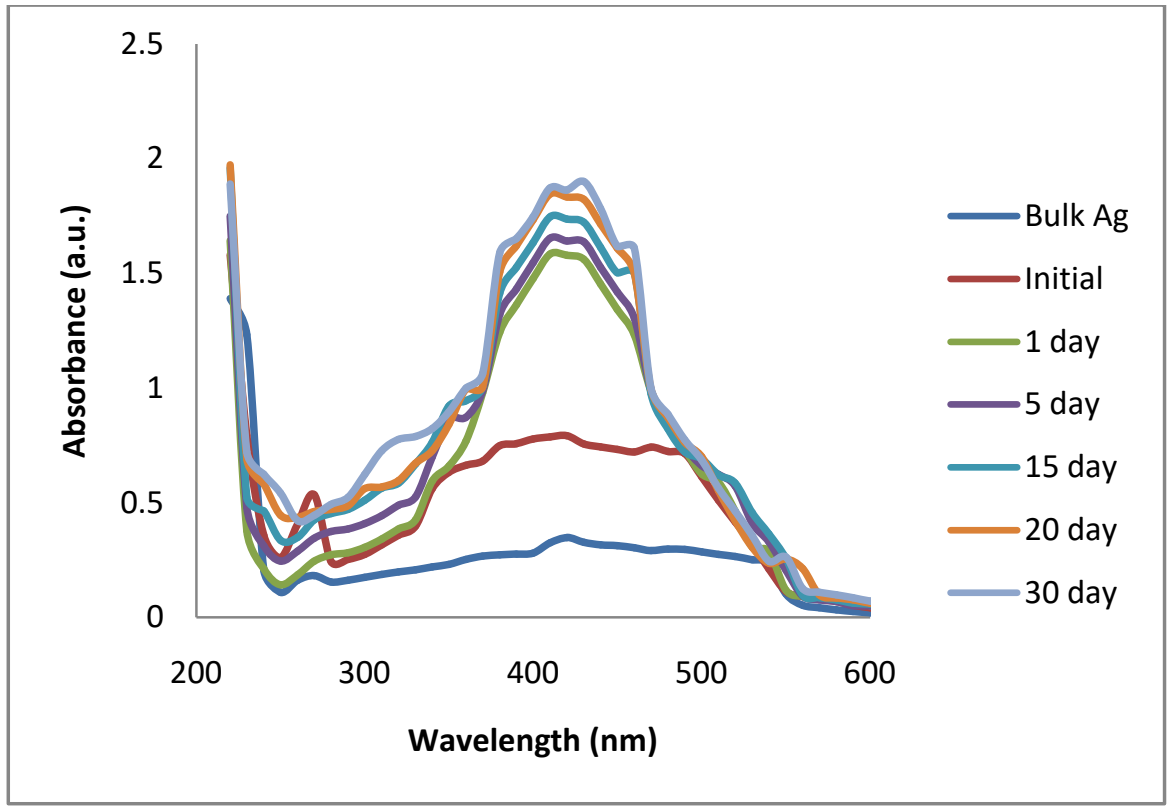

Figure $4 \mathrm{UV}-\mathrm{V}$ is spectra of AgNO3 and algal extract solution

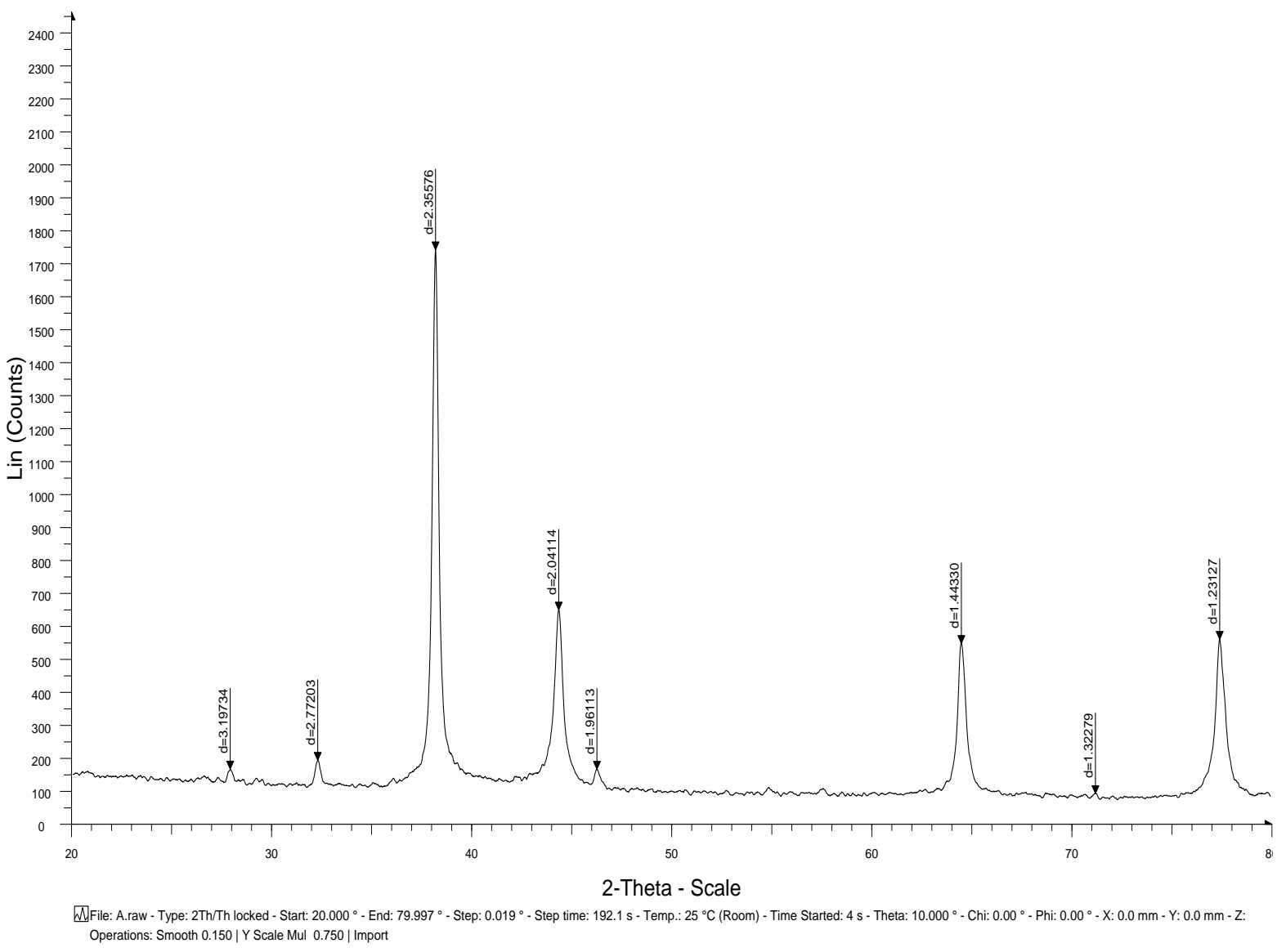

Figure 5 XRD pattern of biosynthesized AgNPs

Journal of Experimental Biology and Agricultural Sciences http://www.jebas.org 


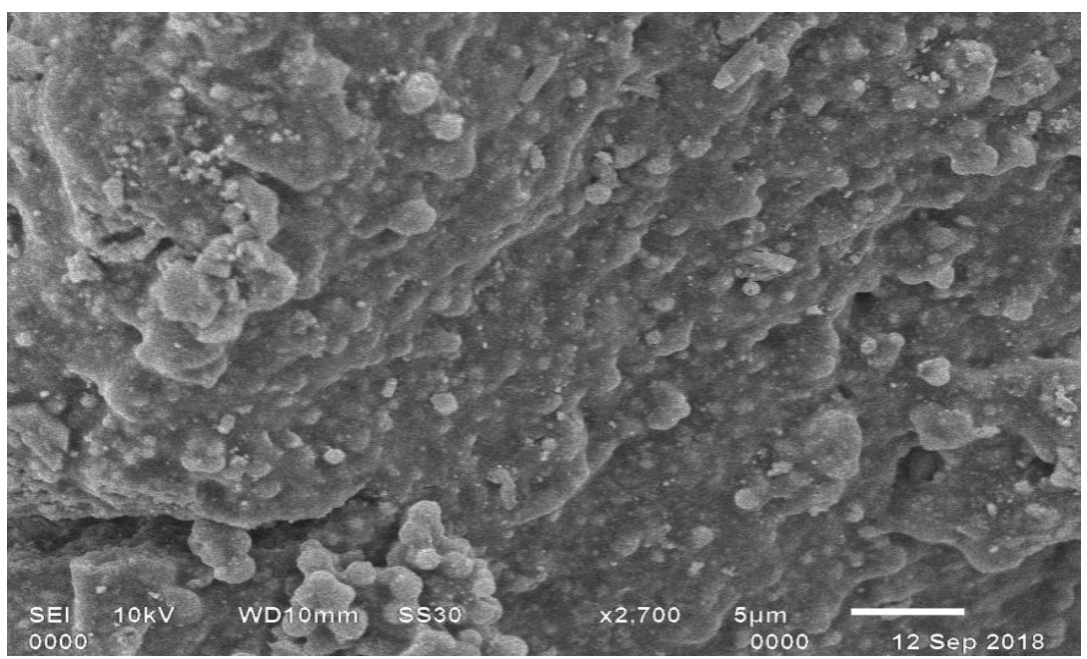

Figure 6 SEM image of AgNPs

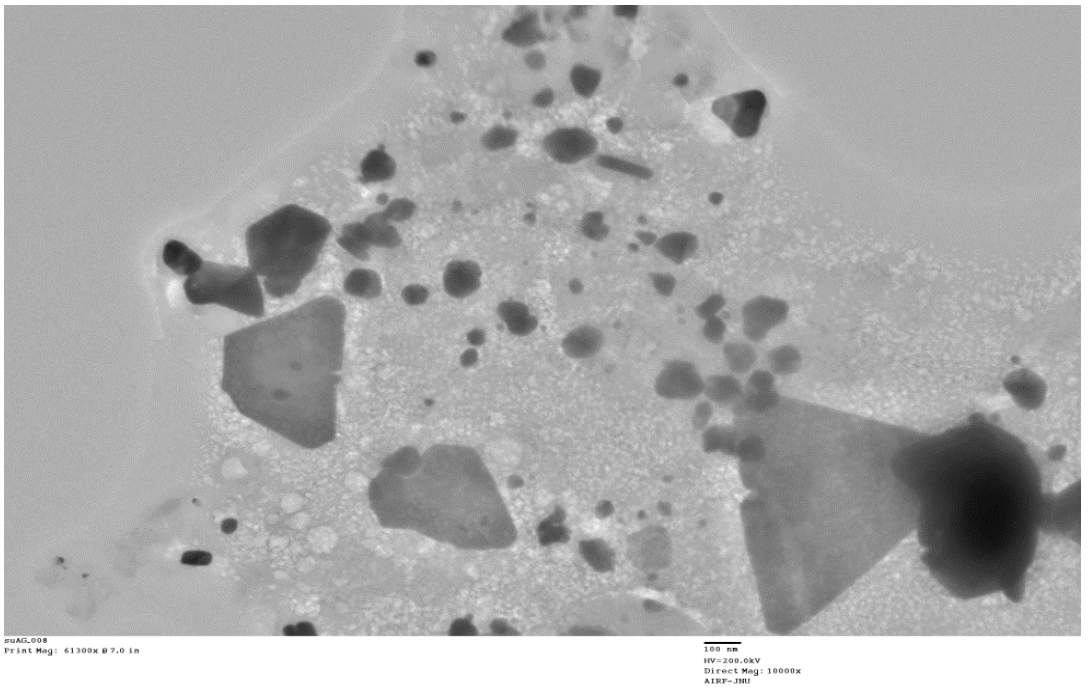

Figure 7 TEM image of AgNPs

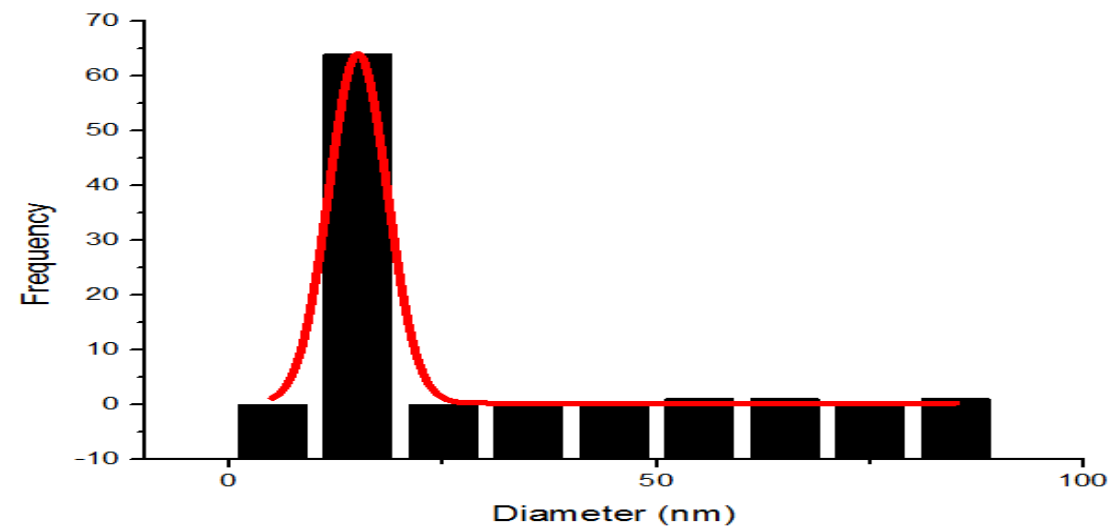

Figure 8 Gaussian particle size distribution of AgNPs 


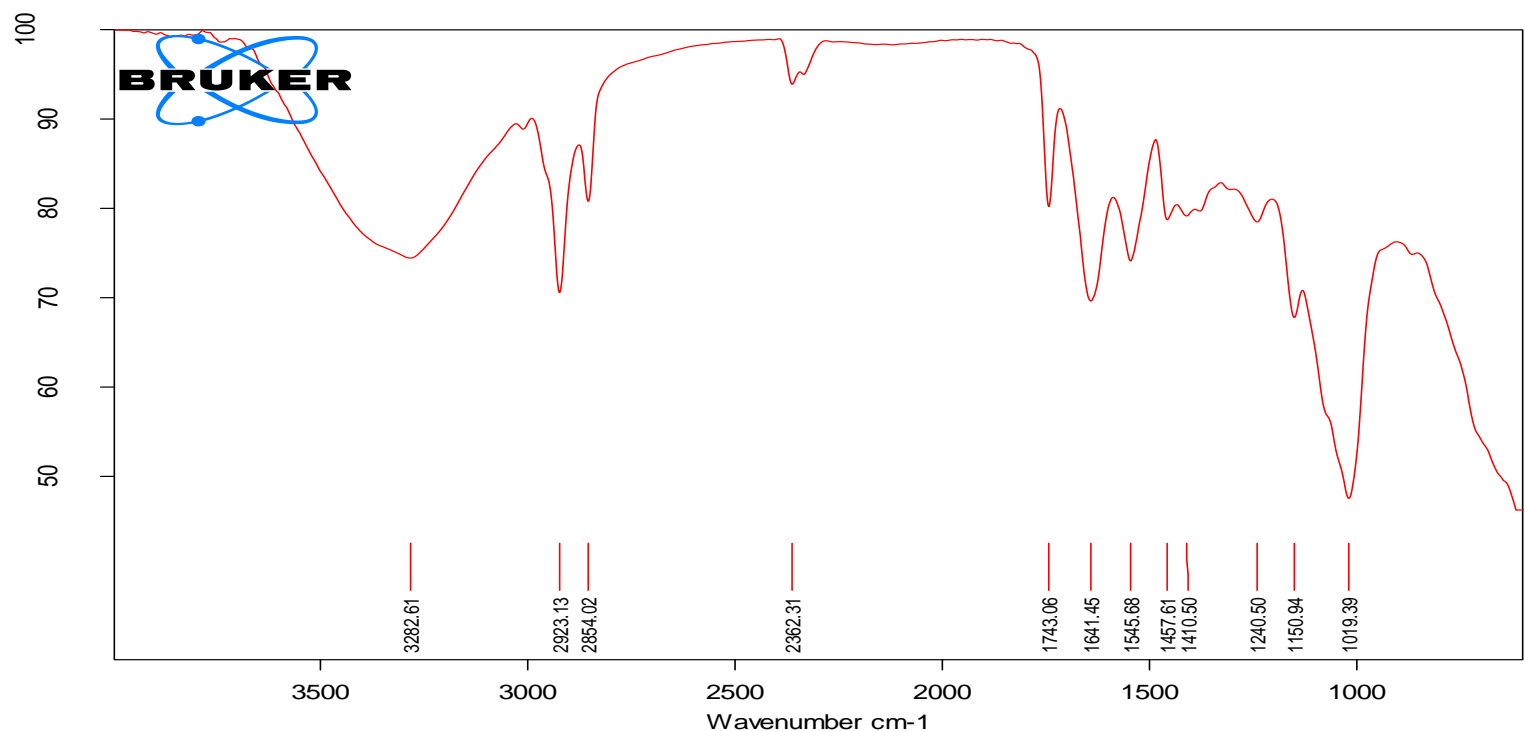

Figure 9 FT-IR analysis of dried algal biomass

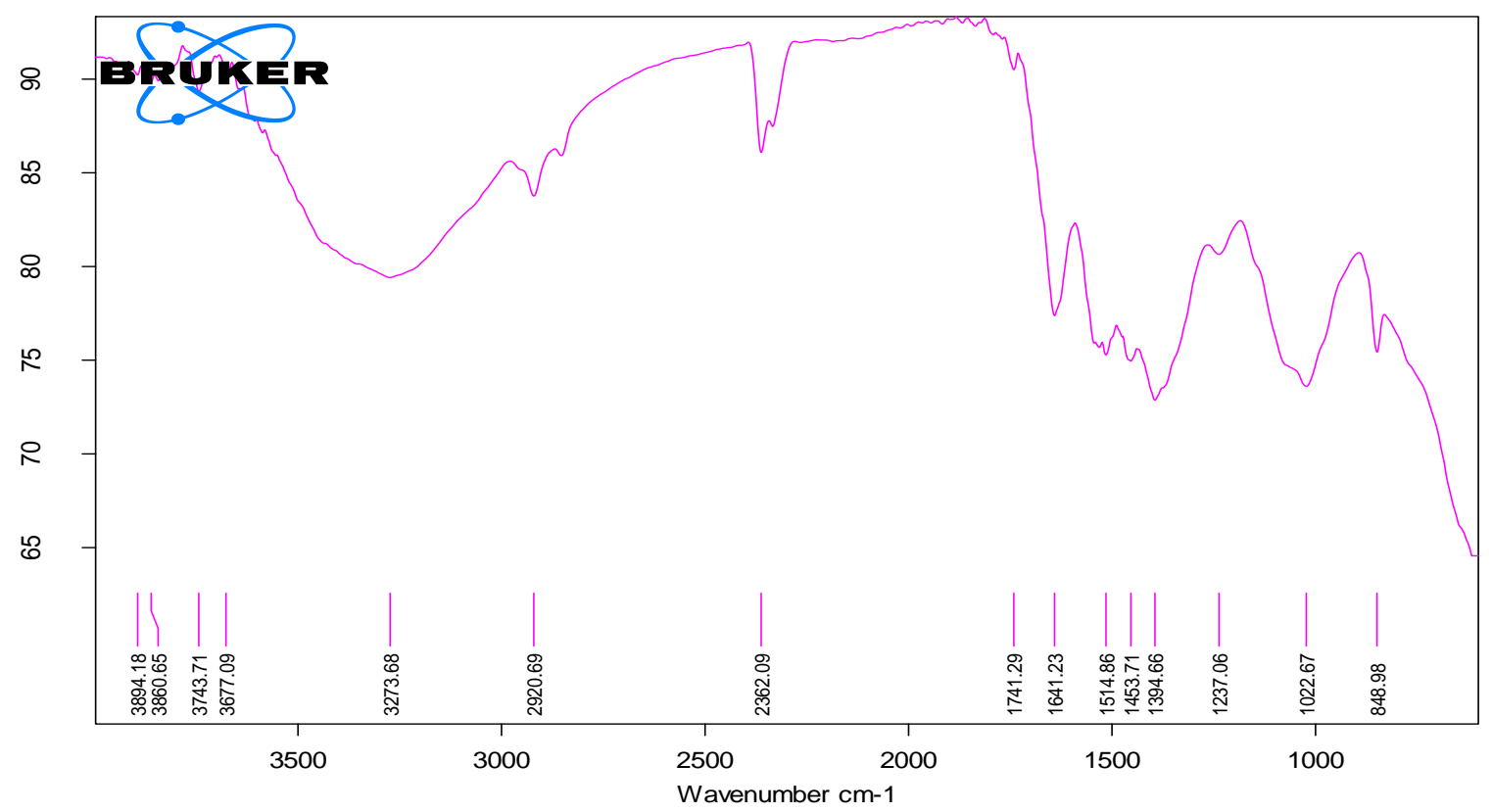

Figure10 FT-IR analysis of biosynthesized AgNPs

The FT-IR analysis was conducted to determine the presence of functional groups responsible for the bioreduction and stabilization of synthesized nanoparticles. The IR spectrum of dried algal biomass indicated the presence of peaks at 1019.39, 1150.94, $1240.50,1410.50,1457.61,1545.68,1641.45,1743.06,2362.31$, 2854.02, 2923.13, and $3282.61 \mathrm{~cm}^{-1}$ (Figure 9). The band positioned at 1743.06 and 3282.61 corresponds to stretching of $(\mathrm{C}=\mathrm{O})$ group and $(\mathrm{O}-\mathrm{H})$ group of polysaccharides respectively. The spectrum band positioned at 2923.13, 2854.02, and 2584.02 $\mathrm{cm}^{-1}$ is due to the stretching of alkanes $(\mathrm{C}-\mathrm{H})$ of Thiol group. The vibrational peak at $1545.68 \mathrm{~cm}^{-1}, 1019.39 \mathrm{~cm}^{-1,}$ and $1641.45 \mathrm{~cm}^{-1}$ are due to the stretching of aliphatic amines $(\mathrm{C}-\mathrm{N})$ and vibration of alkene $(C=C)$ (Yian Zheng, 2012; Aboelfetoh et al., 2017). The peak at $1743.06 \mathrm{~cm}^{-1}$ indicating the vibrational $(-\mathrm{C}=\mathrm{O})$ stretching of fatty acid ester and lipids. The vibrational peak at $1150.94 \mathrm{~cm}^{-1}$ and $1240.50 \mathrm{~cm}^{-}{ }^{1}$ corresponds to (C-O-C) stretching of carbohydrates and polysaccharides and $(\mathrm{P}=\mathrm{O})$ stretching of DNA, RNA, and phospholipids respectively (Jenaa et al., 2014). The 
band is positioned at $1410.50 \mathrm{~cm}^{-1}$ due to the stretching of $(\mathrm{C}-\mathrm{C})$ group of aromatic rings. The analogous band spectra were observed in Ag nanoparticles with a slight shift in the band position and at lower intensities which confirms the involvement of functional groups in the bioreduction and stabilization of nanoparticles. The IR spectrum of biosynthesized Ag nanoparticles indicating the presence of peaks at 848.98, 1022.67, 1237.06, 1394.66, 1453.71, 1514.86, 1641.23, 1741.29, 2362.09, 2920.69, $3273.68,3677.68,3743.71,3860.65$ and $3894.18 \mathrm{~cm}^{-1}$ (Figure 10). In the case of $\mathrm{Ag}$ nanoparticles peak shift of alkanes was observed from 2923.13 to 2920.69 . The IR spectra at $1641.23,1514.86$, and $1022.67 \mathrm{~cm}^{-1}$ exhibited the introduction of primary amines, nitro compounds, and aliphatic amines respectively indicating the bioreduction of AgNPs (Khalid et al., 2017). A slight shift of alkenes and $\mathrm{O}-\mathrm{H}$ stretching was also observed from 1641.45 to $1641.23 \mathrm{~cm}^{-1}$ and 2362.31 to $2362.09 \mathrm{~cm}^{-1}$. The introduction of vibration peak at $1394.66 \mathrm{~cm}^{-1}$ was found related to the amide (II and III) group of aromatic rings possibly due to the association of polyphenols with the synthesized NPs which were extracted from the algal biomass (Rajeshkumar et al., 2012). The slight shift in the peak from 1743.06 to $1741.29 \mathrm{~cm}^{-1}$ and 1240.50 to $1237.06 \mathrm{~cm}^{-}$ ${ }^{1}$ confirms the involvement of lipid biomolecules in the synthesis of AgNPs. The shift in the vibrational peak from 1457.61 to 1453.71 indicates the association of carboxylate ions with the reduced $\mathrm{Ag}$ metal ions (Govindaraju et al., 2015). The shift of peak from 3282.61 to $3273.68 \mathrm{~cm}^{-1}$ confirmed the involvement of polysaccharide biomolecules in the reduction of bulk silver to zerovalent AgNPs. The observed peak at 848.98 indicated the presence of the alkyl halides group. The appearance of vibration peak in the range $3400-3000 \mathrm{~cm}^{-1}$ showed stretching of the hydroxyl group.

\subsection{Batch experiment adsorption study of $\mathrm{Pb}$ (II) using phycosynthesized AgNPs}

It was observed that $\mathrm{Pb}$ (II) and $\mathrm{Cd}$ (II) metal ions were removed from the solution by nanoparticles within $120 \mathrm{~min}$ (Figure 11). The maximum experimental $\mathrm{Pb}$ (II) and $\mathrm{Cd}$ (II) ions removal from the solution using AgNPs were found to be 93.61 \pm 0.3 and $76.66 \pm 0.41 \mathrm{mg} / \mathrm{L}$ respectively. The sorption trend for both the metal ions showed adsorption at 120 min which could be due to the unavailability of binding sites on the surface of nanoparticles; also no further increase in the adsorption of metal ions were recorded.

To determine the effect of hydrogen ion concentration on the adsorption process, the batch experiment was carried out at different $\mathrm{pH}(2.0,4.0,6.0,8.0$, and 10.0) with $100 \mathrm{mg} / \mathrm{L}$ of initial metal ion concentration, $0.5 \mathrm{~g}$ of adsorbent dose, contact time of $120 \mathrm{~min}$, agitation speed of $150 \mathrm{rpm}$ at room temperature. The percent removal of metal ions by nano adsorbent with varying range of $\mathrm{pH}$ is shown in Figure 12. It has been observed that with the increase in $\mathrm{pH}$ from 2 to10 the percent removal of $\mathrm{Pb}$ (II) and
Cd (II) using $\mathrm{Ag}$ nanoparticles was increased. The minimum removal of $\mathrm{Pb}$ (II) and $\mathrm{Cd}$ (II) ion using $\mathrm{Ag}$ nanoparticles as an adsorbent was found to be $10.57 \pm 0.37$ and $5.68 \pm 0.21 \mathrm{mg} / \mathrm{L}$ respectively at $\mathrm{pH} 2.0$ while at $\mathrm{pH} 8.0$ the maximum removal of $\mathrm{Pb}$ (II) and Cd (II) was found to be $82.82 \pm 0.22$ and $78.76 \pm 0.88 \mathrm{mg} /$ L respectively.

To determine the effect of adsorbent dose on the adsorption of selected metal ions, the batch experiment was conducted at different concentration of Ag nanoparticles (0.05, 0.1, 0.2, 0.5, 0.9 $\mathrm{g} / \mathrm{L}$ ), $100 \mathrm{mg} / \mathrm{L}$ of initial metal ion concentration, contact time of $120 \mathrm{~min}, \mathrm{pH}$ as determined in the above experiment. The maximum removal of metal ions was observed at a concentration of $0.5 \mathrm{~g} / \mathrm{L}$. It can be seen in Figure 13 that with an increase in the concentration of adsorbent the removal efficiency increased which could be possibly due to the increase in the number of binding sites which in return facilitates the adsorption process. However, after a certain amount of adsorbent dose, the removal efficiency remains constant and no further removal of metal ion was observed. AgNPs were found responsible for the maximum removal of $\mathrm{Pb}$ (II) and Cd (II), i.e. $97.55 \pm 0.14$ and $93.83 \pm 0.29 \mathrm{mg} / \mathrm{L}$ respectively and minimum removal of concentration was $8.68 \pm 0.32$ and $8.72 \pm 0.21$ $\mathrm{mg} / \mathrm{L}$ at $0.05 \mathrm{~g} / \mathrm{L}$ of adsorbent dose. It has been suggested that at a higher adsorbent dose heavy metal adsorption reduces as metal ions are not sufficient to cover all the adsorption sites available on the adsorbent surface (Sivaprakash et al., 2009).

To determine the influence of concentration of initial metal ion on their adsorption on the surface of adsorbent an experiment was conducted in batch mode using different metal ion concentration $(50,100,150,200,250$, and $300 \mathrm{mg} / \mathrm{L})$, adsorbent dose $(0.5 \mathrm{~g} / \mathrm{L})$, agitation speed $(150 \mathrm{rpm}), \mathrm{pH}$ as determined in the above experiment. In the case of $\mathrm{Ag}$ nanoparticles as an adsorbent, the maximum removal of $\mathrm{Pb}$ (II) and $\mathrm{Cd}$ (II) ions was $45.67 \pm 0.25$ and $40.44 \pm 0.97 \mathrm{mg} / \mathrm{L}$ respectively at $50 \mathrm{mg} / \mathrm{L}$ of initial metal concentration (Figure 14). It is also evident from the observations that with the increase in the metal ion concentration the percent removal decreases which could be possibly due to the lesser number of available active binding sites on the adsorbent surface for the higher concentration of adsorbate. It was supported by the fact that at a lower concentration of adsorbate more vacant adsorption sites are available for sorption, hence more uptake of metal ions takes place (Al-Qahtani, 2017).

To determine the effect of temperature on adsorption, the batch experiment was conducted at different temperatures $(5,20,35,50$, 65 , and $80^{\circ} \mathrm{C}$ ), initial metal ion concentration $(100 \mathrm{mg} / \mathrm{L})$, adsorbent dose $(0.5 \mathrm{~g} / \mathrm{L})$, contact time $(120 \mathrm{~min})$ and $\mathrm{pH}$ (as determined in the above experiments). The maximum removal of $\mathrm{Pb}$ (II) and Cd (II) metal ion by $\mathrm{Ag}$ nanoparticles was $96.07 \pm 0.31$ $\mathrm{mg} / \mathrm{L}$ and $80.89 \pm 0.08 \mathrm{mg} / \mathrm{L}$ at $5^{\circ} \mathrm{C}$ and minimum removal was $2.85 \pm 0.45$ and $3.63 \pm 0.21 \mathrm{mg} / \mathrm{L}$ at $80^{\circ} \mathrm{C}$ respectively (Figure 15). 


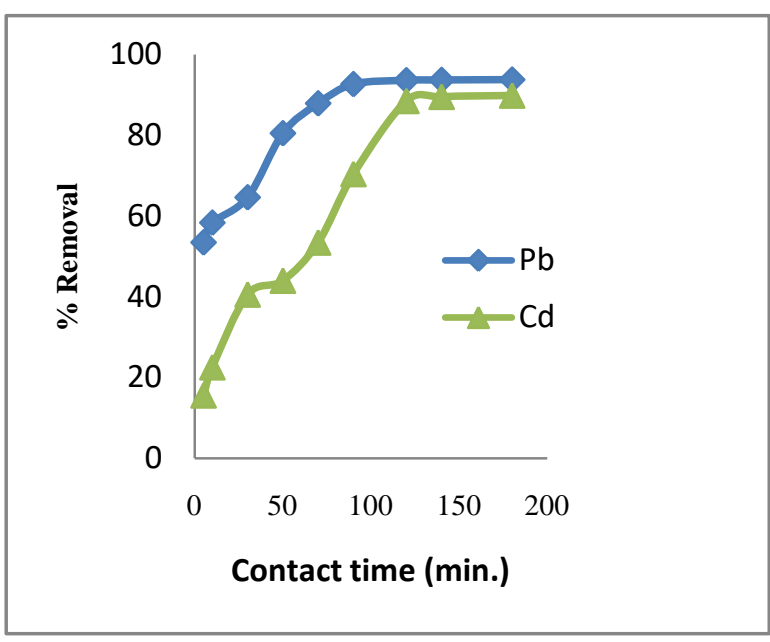

Figure11 Effect of time of contact on adsorption of $\mathrm{Pb}$ (II) and Cd (II) by Ag nanoparticles

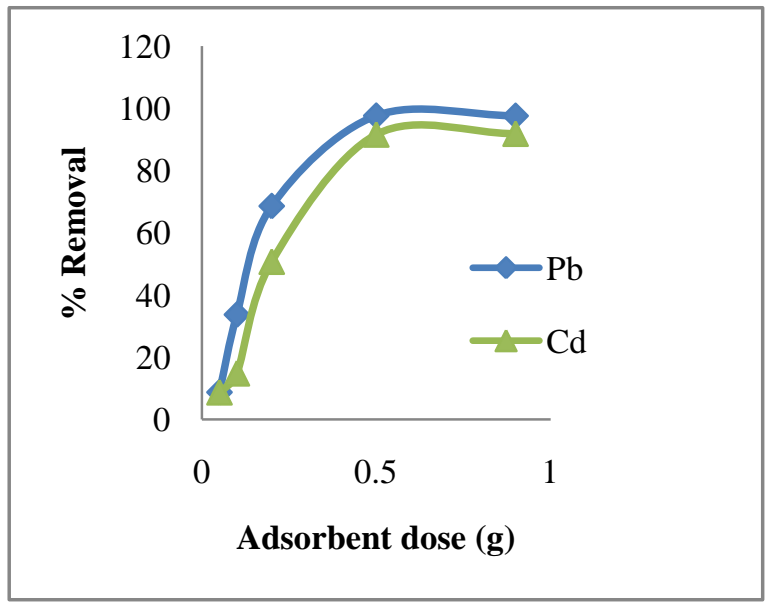

Figure13 Effect of Adsorbent dose on adsorption of $\mathrm{Pb}$ (II) and $\mathrm{Cd}$ (II) by $\mathrm{Ag}$ nanoparticles

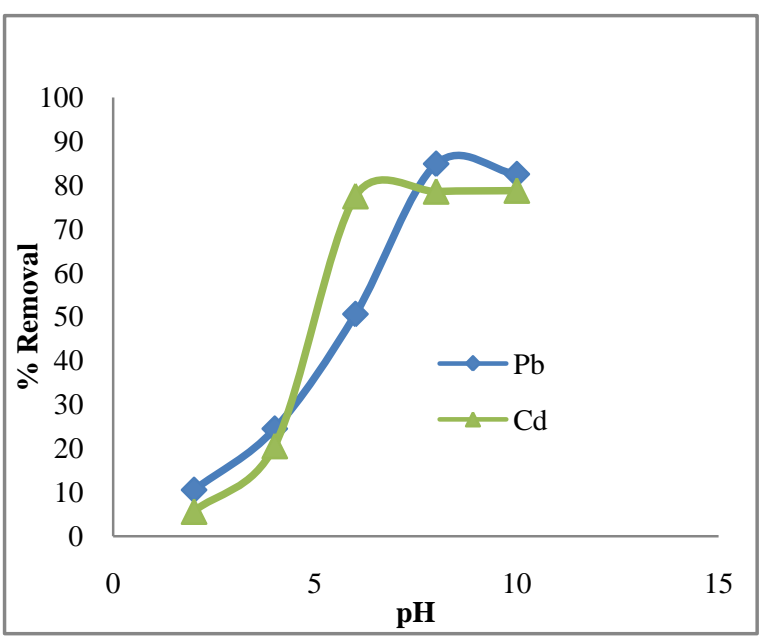

Figure12 Effect of $\mathrm{pH}$ on adsorption of $\mathrm{Pb}$ (II) and $\mathrm{Cd}$ (II) by Ag nanoparticles

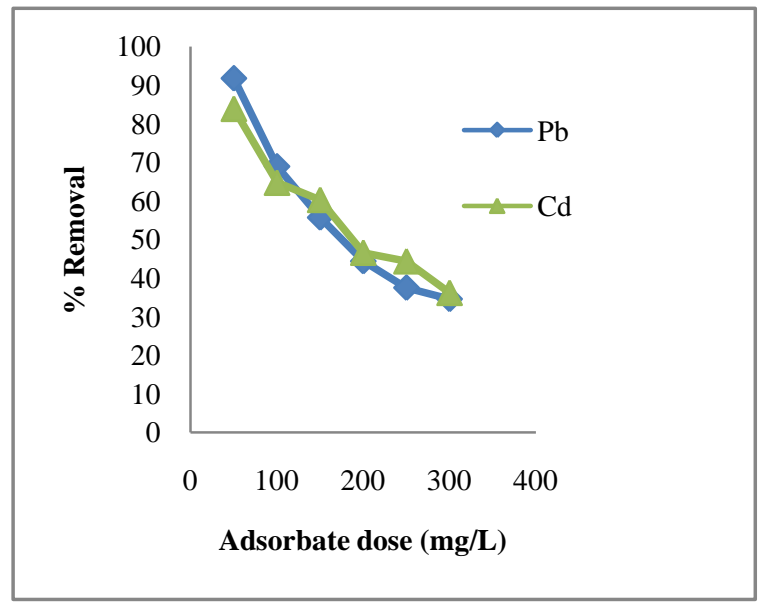

Figure14 Effect of adsorbate dose on adsorption of $\mathrm{Pb}$ (II) and Cd (II) by Ag nanoparticles

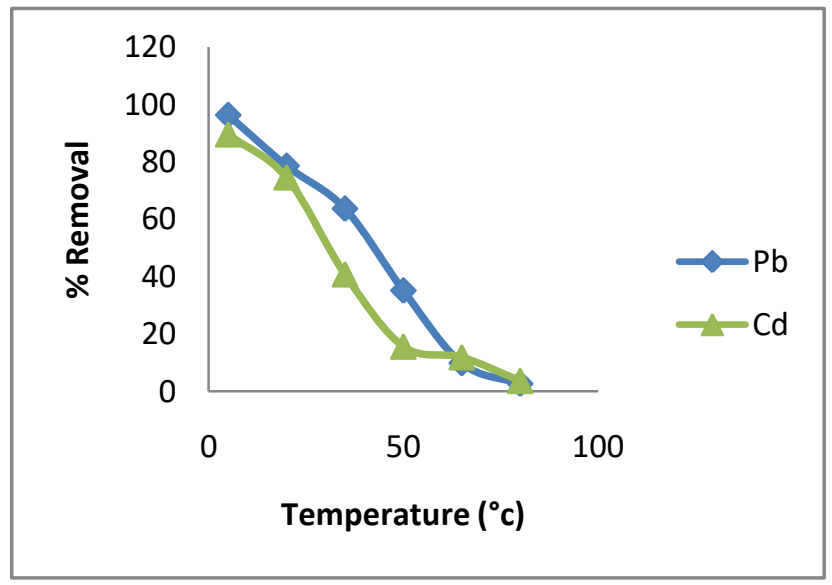

Figure15 Effect of temperature on adsorption of $\mathrm{Pb}$ (II) and Cd (II) by $\mathrm{Ag}$ nanoparticles

Journal of Experimental Biology and Agricultural Sciences http://www.jebas.org 


\subsection{Study on adsorption isotherm}

The equilibrium study on $\mathrm{Pb}$ (II) and $\mathrm{Cd}$ (II) metal ion removal was carried out using varying amount of initial metal ion concentration from 50 to $300 \mathrm{mg} / \mathrm{L}$, adsorbent dose $(0.5 \mathrm{~g} / \mathrm{L})$, room temperature, the volume of the metal ion solution $(100 \mathrm{ml})$, equilibrium time $(120 \mathrm{~min})$, agitation speed $(150 \mathrm{rpm})$ and at their native $\mathrm{pH}$. The parameters/ constants of Freundlich and Langmuir isotherm for $\mathrm{Pb}$ (II) and $\mathrm{Cd}$ (II) $\mathrm{Ag}$ nanoparticles as adsorbents are listed in Table 1. Linear plots of Langmuir isotherm for $\mathrm{Pb}$ (II) and $\mathrm{Cd}$ (II) using Ag nanoparticles as adsorbents are shown in Figure 16 (a \& b). Linear plots of Freundlich isotherm for $\mathrm{Pb}$ (II) and $\mathrm{Cd}$ (II) using Ag nanoparticles adsorbents are shown in Figure 17 (a \& b).

The two parameters of Langmuir isotherm; KL and q0 measure the affinity of adsorption sites and maximum adsorbent capacity respectively. The maximum value of metal ion adsorption capacity (23.98 mg/g) was observed for $\mathrm{Pb}$ (II) (Table 1). AgNPs showed a stronger binding affinity towards $\mathrm{Cd}$ (II). The value of the equilibrium parameter (RL) showed that the nature of adsorption of the metal ion by Ag nanoparticles is favourable as $0<\mathrm{R}<1$. The two parameters of Freundlich isotherm; $n$ and KF, measure the affinity of adsorption sites and maximum adsorbent capacity respectively. The higher value of $\mathrm{R}^{2}$ showed that the experimental data were fitted best with Langmuir isotherm than with Freundlich isotherm using Ag nanoparticles. Several studies have explained the equilibrium data for $\mathrm{Pb}$ (II) and $\mathrm{Cd}$ (II) with the help of Langmuir and Freundlich adsorption isotherm using AgNPs (Poguberović et al., 2016; Al-Qahtani, 2017; El-Sabban et al., 2020).

Table 1Parameters of adsorption isotherms for $\mathrm{Pb}$ (II) and $\mathrm{Cd}$ (II) adsorption on $\mathrm{Ag}$ nanoparticles

\begin{tabular}{|c|c|c|c|c|c|c|}
\hline \multirow{2}{*}{ Metal ion } & \multicolumn{3}{|c|}{ Langmuir isotherm } & \multicolumn{3}{|c|}{ Freundlich isotherm } \\
\hline & $\mathrm{K}_{\mathrm{L}}(\mathrm{L} / \mathrm{mg})$ & $\mathrm{q}_{0}(\mathrm{mg} / \mathrm{g})$ & $\mathrm{R}^{2}$ & $\mathrm{n}$ & $\mathrm{K}_{\mathrm{F}}(\mathrm{mg} / \mathrm{g})$ & $\mathrm{R}^{2}$ \\
\hline $\mathrm{Pb}$ (II) & 0.0304 & 23.98 & 0.990 & 2.7005 & 1.622 & 0.961 \\
\hline $\mathrm{Cd}(\mathrm{II})$ & 0.041 & 22.47 & 0.994 & 3.0211 & 1.831 & 0.959 \\
\hline
\end{tabular}

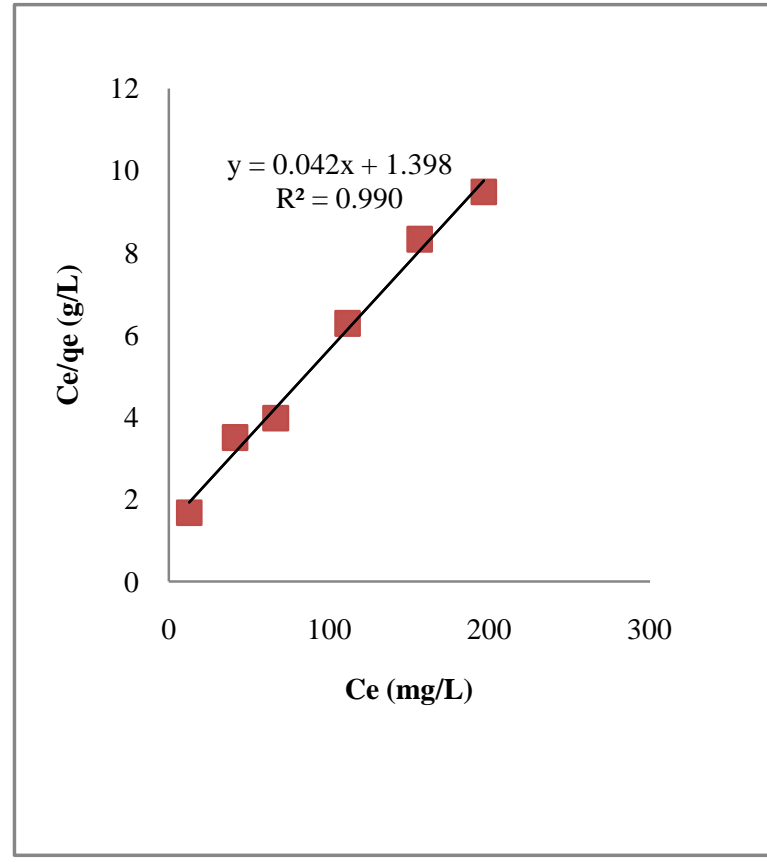

Figure16 (a) Langmuir adsorption isotherm plot of $\mathrm{Pb}$ (II) ion using Ag nanoparticles

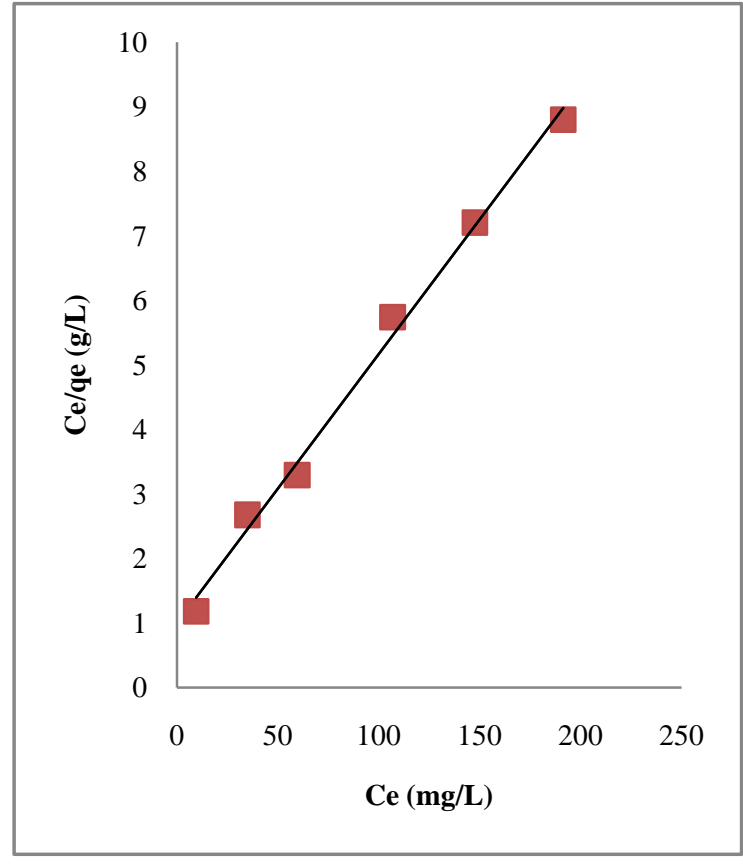

Figure16 (b) Langmuir adsorption isotherm plot of Cd (II) ion using $\mathrm{Ag}$ nanoparticles 


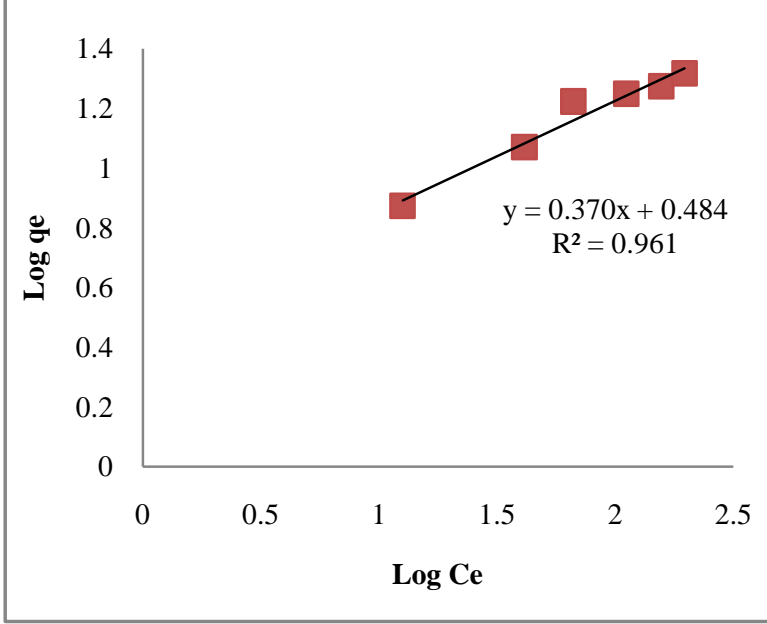

Figure17 (a) Freundlich adsorption isotherm plot of $\mathrm{Pb}$ (II) ion using AgNPs

\subsection{Adsorption kinetics}

To determine the adsorption rate of metal ions on nanoparticles pseudo-first order and pseudo- second order kinetic models were used in the present study. The equilibrium study on $\mathrm{Pb}$ (II) and $\mathrm{Cd}$ (II) metal ion removal was carried out at the different time of contact from 5 to $120 \mathrm{~min}$, adsorbent dose $(0.5 \mathrm{~g} / \mathrm{L})$, the volume of the metal ion solution $(100 \mathrm{ml})$, adsorbate dose $(100 \mathrm{mg} / \mathrm{L})$, agitation speed $(150 \mathrm{rpm})$ and at their native $\mathrm{pH}$. The best fitted model was selected based on a higher value of linear correlation coefficient $\left(\mathrm{R}^{2}\right)$ and the similar value obtained from theoretical and experimental data. The experimental data obtained from adsorption process was fitted in the above-mentioned kinetic models to calculate the metal uptake by adsorbents at a different time of contact.

The calculated parameters of pseudo-first order and pseudo-second order rate kinetic models for $\mathrm{Pb}$ (II) and $\mathrm{Cd}$ (II) using $\mathrm{Ag}$ nanoparticles as adsorbent are shown in Table 2 by plotting log (qe-qt) against time $t$ the parameters of pseudo $1^{\text {st }}$ order were determined from slope and intercept of the plot (Figure 18 \& 19) while by plotting t/qt against time $t$, the parameters of pseudo $2^{\text {nd }}$

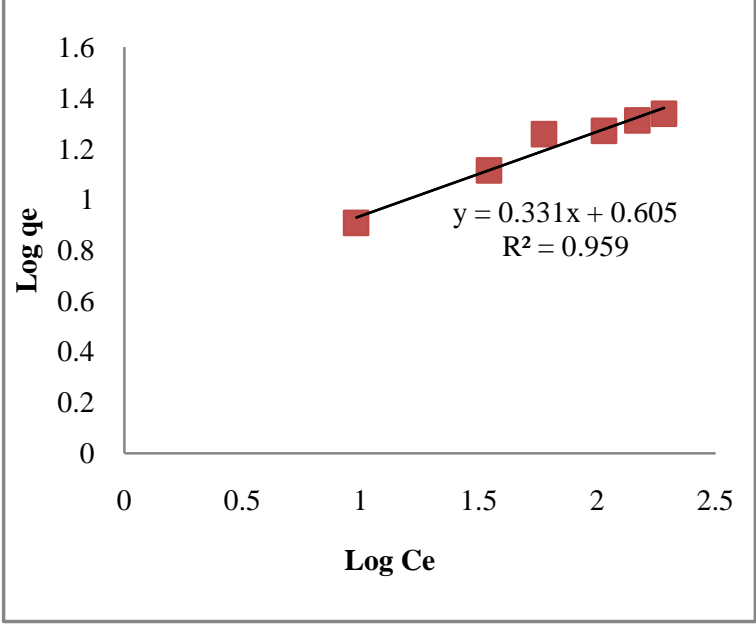

Figure 17 (b) Freundlich adsorption isotherm plot of Cd (II) ion using AgNPs

order were determined from slope and intercept of the plot (Figure $20 \& 21$ ). Both the rate kinetic models were used to simulate the experimentally obtained data for $\mathrm{Pb}$ (II) and $\mathrm{Cd}$ (II) $\mathrm{Ag}$ nanoparticles as adsorbents.

Using $\mathrm{Ag}$ nanoparticles the uptake of $\mathrm{Pb}$ (II) metal ion showed a higher value of $\mathrm{R}^{2}$ i.e.0.93 and maximum adsorption capacity of $23.14 \mathrm{mg} / \mathrm{g}$ respectively, hence it can be concluded that $\mathrm{Pb}$ (II) followed pseudo $2^{\text {nd }}$ order kinetic model and chemisorption was responsible for the interaction of metal ion with the adsorbent (Alia et al., 2018). On the contrary, it was observed that the linear correlation coefficient of $\mathrm{Cd}$ (II) is very low in the case of pseudo $2^{\text {nd }}$ order model and also the experimental qe value and calculated qe value do not match appropriately but fitted well with pseudo $1^{\text {st }}$ order kinetic model hence it can be concluded that physical adsorption is responsible for $\mathrm{Cd}$ (II) metal ion uptake by $\mathrm{Ag}$ nanoparticles. Few studies have reported the application of kinetic models with pseudo- first order and pseudo- second order equations to examine successful adsorption of $\mathrm{Pb}$ (II) and $\mathrm{Cd}$ (II) ion using nanoparticles as an adsorbent (Abdollahi et al., 2018; Salam et al., 2020; Lin et al., 2020).

Table 2 Values of parameters of pseudo $1^{\text {st }}$ and $2^{\text {nd }}$ order kinetic models using Ag nanoparticles as an adsorbent

\begin{tabular}{|c|c|c|c|c|c|c|}
\hline \multirow[b]{2}{*}{ Metal ion } & \multicolumn{3}{|c|}{ Pseudo 1 order } & \multicolumn{3}{|c|}{ Pseudo $2^{\text {nd }}$ order } \\
\hline & $\mathrm{K}_{1}$ & $\mathrm{q}_{\mathrm{e}}(\mathrm{mg} / \mathrm{g})$ & $\mathrm{R}^{2}$ & $\mathrm{~K}_{2}$ & $\mathrm{q}_{\mathrm{e}}(\mathrm{mg} / \mathrm{g})$ & $\mathrm{R}^{2}$ \\
\hline $\mathrm{Pb}$ (II) & 0.0479 & 5.697 & 0.874 & 0.00186 & 23.14 & 0.930 \\
\hline Cd (II) & 0.0474 & 5.476 & 0.883 & -0.0053 & -13.62 & 0.1442 \\
\hline
\end{tabular}

Journal of Experimental Biology and Agricultural Sciences http://www.jebas.org 


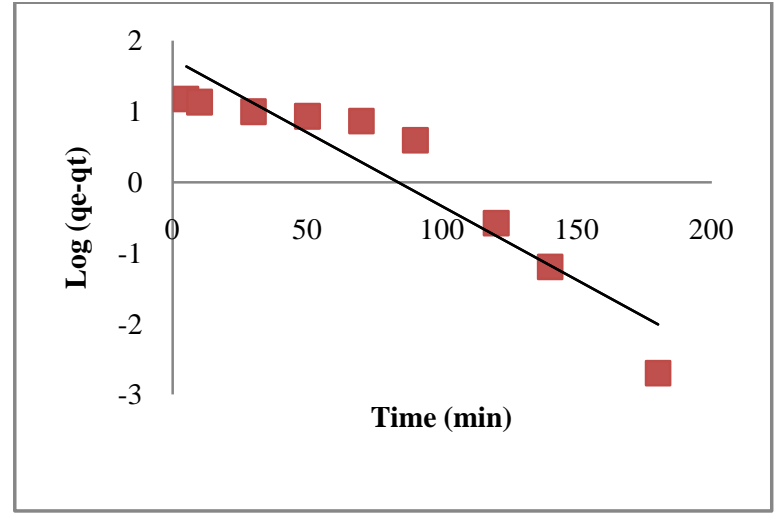

Figure 18 Pseudo-first order kinetic model for $\mathrm{Pb}$ (II) using Ag nanoparticles

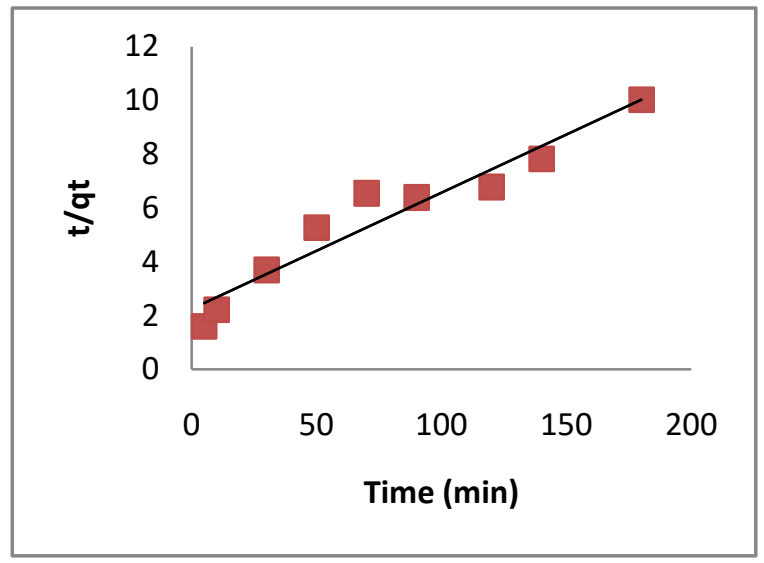

Figure 20 Pseudo-second order kinetic model for $\mathrm{Pb}$ (II) using Ag nanoparticles

\section{Conclusion}

An eco-friendly and cost-effective approach has been employed for the synthesis of AgNPs and was examined for their efficiency in the removal of metal ions from an aqueous solution. In the present study, Ag nanoparticles were synthesized using an aqueous extract of microalgae characterized as Tetradesmus sp. based on morphological and DNA gene sequencing at the ITS region. The initial change in colour of the reaction mixture confirmed the synthesis of nanoparticles. UV-Vis spectroscopy showed absorption peak at $411 \mathrm{~nm}$ indicating a reduction in the size of bulk AgNPs. XRD, SEM, and TEM analysis confirmed the spherical shape and crystalline nature of biosynthesized $\mathrm{Ag}$ nanoparticles with an average particle size $15 \mathrm{~nm}$. The FT-IR spectra clearly showed the vibrational stretching of the functional group present on protein, carbohydrate, and lipids confirming the involvement of these biomolecules in size reduction and stabilization of

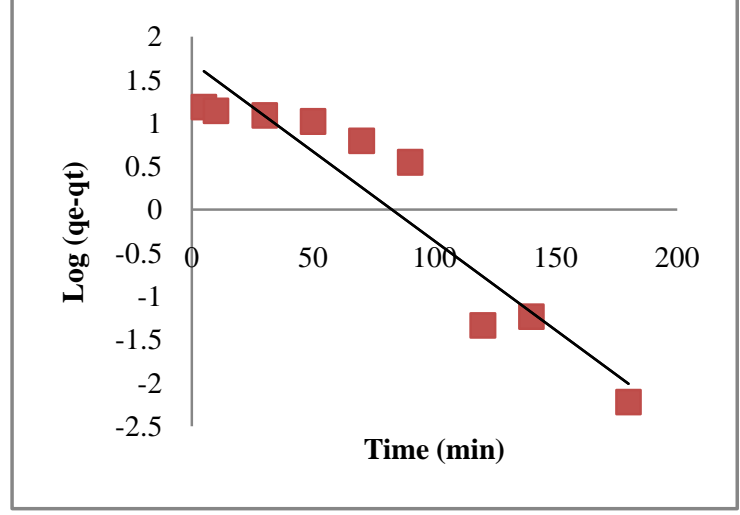

Figure 19 Pseudo-first order kinetic model for Cd (II) using Ag nanoparticles

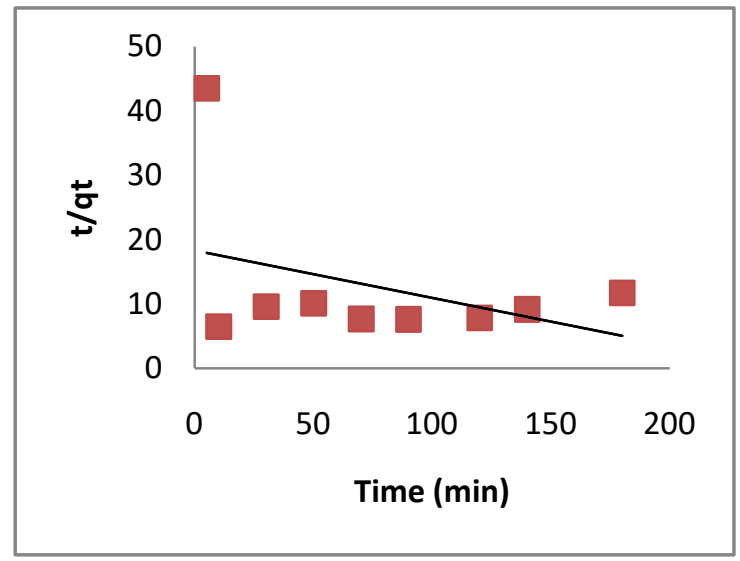

Figure 21 Pseudo-second order kinetic model for Cd (II) using Ag nanoparticles

nanoparticles. The equilibrium time of $120 \mathrm{~min}$ was recorded for the maximum removal of $\mathrm{Pb}$ (II) and $\mathrm{Cd}$ (II) ions using $\mathrm{Ag}$ nanoparticles. The maximum removal of $\mathrm{Pb}$ (II) (II) was observed at $\mathrm{pH} 8.0$ due to higher electronegativity as compared to Cd (II) ion. The study on the effect of initial metal concentration on adsorption of metal ions showed maximum removal at lower metal concentration, i.e. $50 \mathrm{mg} / \mathrm{L}$. The maximum removal of both the metal ions was observed at adsorbent dose of $0.5 \mathrm{~g} / \mathrm{L}$. The removal of $\mathrm{Pb}$ (II) and $\mathrm{Cd}$ (II) by $\mathrm{Ag}$ nanoparticles was observed sharply when nanoparticle concentration ranged between 0.05-0.5 g/L. The maximum removal of metal ions at lower temperatures signifies an exothermic adsorption process. The experimental data obtained from the batch experiment were best fitted in the Langmuir isotherm adsorption isotherm model $\left(\mathrm{R}^{2}>0.99\right)$. The $\mathrm{Ag}$ nanoparticles showed maximum adsorption capacity for $\mathrm{Pb}$ (II) $(23.98 \mathrm{mg} / \mathrm{g})$ and higher affinity towards Cd (II) indicating the selective removal of the metal ion by nanoadsorbent. It was 
observed that the adsorption of $\mathrm{Pb}$ (II) and Cd (II) ions on AgNPs followed pseudo-second-order kinetics (R2>0.9) and pseudo-firstorder kinetics (R2>0.8) respectively. Therefore, it can be concluded that $\mathrm{Ag}$ nanoparticles can be used efficiently in water/wastewater treatment as an adsorbent. Further research aims at evaluating the usability and stability of catalyst AgNps. Future research needs to be focused on determining the fate of waste generated and evaluating the cost-effectiveness of biologically synthesized nanoparticles for economic designing of water treatment plants.

\section{Acknowledgement}

The authors are pleased to acknowledge G.B. Pant University of Agriculture and Technology for providing resources and facilities to carry out the present research work and IIT Roorkee for providing TEM and XRD Instrumentation facilities.

\section{Conflict of interest}

The authors declare that there is no conflict of interest.

\section{References}

Abdollahi B, Shakeri A, Aber S, Bonab SA (2018) Simultaneous photodegradation of acid orange 7 and removal of $\mathrm{Pb}^{2+}$ from polluted water using reusable clinoptilolite- $\mathrm{TiO}_{2}$ nanocomposite. Research on Chemical Intermediates 44: 15051521.

Abegunde SM, Idowu KS, Sulaimon AO (2020) Plant-Mediated Iron Nanoparticles and their Applications as Adsorbents for Water Treatment-A Review. Journal of Chemical Reviews 2(2): 103-113.

Aboelfetoh EF, El-Shenody RA, Ghobara MM (2017) Eco-friendly synthesis of silver nanoparticles using green algae (Caulerpa serrulata): reaction optimization, catalytic and antibacterial activities. Environmental Monitoring and Assessment 189: 349.

Ali I, Peng C, Khan ZM, Sultan M, Naz I (2018) Green Synthesis of Phytogenic Magnetic Nanoparticles and Their Applications in the Adsorptive Removal of Crystal Violet from Aqueous Solution. Arabian Journal for Science and Engineering 43: 62456259.

Alia A, Mannanb A, Hussainc I, Hussaind I, Zia M (2018) Effective removal of metal ions from aqueous solution by silver and zinc nanoparticles functionalized cellulose: Isotherm, kinetics and statistical supposition of process. Environmental Nanotechnology, Monitoring \& Management 9: 1-11.

Al-Qahtani KM (2017) Cadmium removal from aqueous solution by green synthesis zero valent silver nanoparticles with Benjamina leaves extract. Egyptian Journal of Aquatic Research 43: 269-274.
Aravind M, Ahmad A, Ahmad I, Amalanathan M, Naseem K, Mary SMM, Parvathiraja C, Hussain S, Algarni TS, Pervaiz M, Zuber M (2021) Critical green routing synthesis of silver NPs using jasmine flower extract for biological activities and photocatalytical degradation of methylene blue. Journal of Environmental Chemical Engineering 9: 104877.

Chaidir Z, Fadjria N, Armaini, Zainu R (2016) Isolation and molecular identification of freshwater microalgae in Maninjau Lake West Sumatra. Der Pharmacia Lettre 8(20): 177-187.

Chandra C, Khan F (2020) Nano scale zerovalent nickel: Green synthesis, characterization, and efficient removal of lead from aqueous solution. Inorganic and Nano-Metal Chemistry 50: 10441052.

Dağlığlu Y, Öztürk BY (2019) A novel intracellular synthesis of silver nanoparticles using Desmodesmus sp. (Scenedesmaceae): different methods of pigment change. Rendiconti Lincei. Scienze Fisiche e Naturali 30: 611 - 621. Doi: 10.1007/s12210-01900822-8.

El-Sabban H, Eid M, Moustafa Y, Mottaleb MA (2020) Pomegranate peel extract in situ assisted photosynthesis of Silver Nanoparticles decorated Reduced Graphene Oxide as superior sorbents for $\mathrm{Zn}$ (II) and Lead(II). Egyptian Journal of Aquatic Biology \& Fisheries 24: 525 - 539 .

El-Sheekh MM, El-Kassas HY (2016) Algal production of nanosilver and gold: Their antimicrobial and cytotoxic activities: A review. Journal of Genetic Engineering and Biotechnology 14(2): 299-310.

El-Sheekh MM, Shabaan MT, Hassan L, Morsi HH (2020) Antiviral activity of algae biosynthesized silver and gold nanoparticles against Herps Simplex (HSV-1) virus in vitro using cell-line culture technique. International Journal of Environmental Health Research, DOI: 10.1080/09603123.2020.1789946

Freundlich H (1907) Ueber die adsorption in Loesungen. Zeitschrift für Physikalische Chemie57: 385-470.

Ge F, Li MM, Ye H, Zhao B (2012) Effective removal of heavy metal ions $\mathrm{Cd} 2+, \mathrm{Zn} 2+, \mathrm{Pb} 2+, \mathrm{Cu} 2+$ from aqueous solution by polymer-modified magnetic nanoparticles. Journal of Hazardous Materials 211-212: 366-372. Doi: 10.1016/j.jhazmat.2011.12.013.

Govindaraju K, Suganya KSU, Kumar VG, Dhas TS, Karthick V, Singaravelu G, Elanchezhiyan M (2015) Blue green alga mediated synthesis of gold nanoparticles and its antibacterial efficacy against Gram positive organisms. Materials Science and Engineering 47: $351-356$ 
Goyal P, Tiwary CS, Misra SK (2021) Ion exchange based approach for rapid and selective $\mathrm{Pb}$ (II) removal using iron oxide decorated metal organic framework hybrid. Journal of Environmental Management $\quad 277$ : 111469 https://doi.org/10.1016/j.jenvman.2020.111469.

Guiry MD, Guiry GM (2015) Algae Base. World-wide electronic publication, National University of Ireland, Galway. Retrieved from http://www.algaebase.org.

Ho YS, McKay G (2000) The kinetics of sorption of divalent metal ions onto sphagnum moss peat. Water Resource 34 (3): 735-742.

Ifijen IH, Itua $\mathrm{AB}$, Maliki M, Ize-Iyamu $\mathrm{CO}$, Omorogbe SO, Aigbodion AI, Ikhuoria EU (2020) The removal of nickel and lead ions from aqueous solutions using green synthesized silica microparticles. Heliyon 6: e04907.

Jabir MS, Saleh, YM, Sulaiman GM, Yaseen NY, Sahib UI, Dewir YH, Alwahibi MS, Soliman DA (2021) Green Synthesis of Silver Nanoparticles Using Annona muricata Extract as an Inducer of Apoptosis in Cancer Cells and Inhibitor for NLRP3 Inflammasome via Enhanced Autophagy. Nanomaterials 11: 384 https://doi.org/10.3390/nano11020384.

Jenaa J, Pradhana N, Dashb BP, Suklaa LB, Pandaa PK (2014) Biosynthesis and characterization of silver nanoparticles using microalga Chlorococcum humicola and its antibacterial activity. International Journal of Nanomaterials and Biostructures 3(1): 1-8.

Karthik C, Suresh S, Sneha Mirulalini G, Kavitha S (2020) A FTIR approach of green synthesized silver nanoparticles by Ocimum sanctum and Ocimum gratissimum on mung bean seeds. Inorganic and Nano-Metal Chemistry 50: 606-612.

Khalid M, Khalid N, Ahmed I, Hanif R, Ismail M, Janjua HA (2017) Comparative studies of three novel freshwater microalgae strains for synthesis of silver nanoparticles: insights of characterization, antibacterial, cytotoxicity and antiviral activities. Journal of Applied Phycology 29: 1851-1863.

Lagergren S (1898) About the theory of so-called adsorption of soluble substances. Kungliga Svenska Vetenskapsakademiens Handlingar 24(4):1-39.

Langmuir I (1918) The Adsorption of Gases on Plane Surface of Glass, Mica and Platinum. The Research Laboratory of the General Electric Company 40: 1361-1402.

Lin Z, Weng X, Owens G, Chen Z (2020) Simultaneous removal of $\mathrm{Pb}$ (II) and rifampicin from wastewater by iron nanoparticles synthesized by a tea extract. Journal of Cleaner Production 242: 118476.
Mandal S, Marpu S, Hughes R, Omary M, Shi S (2021) Green Synthesis of Silver Nanoparticles Using Cannabis sativa Extracts and Their Anti-Bacterial Activity. Green and Sustainable Chemistry 11: 38-48

Patel V, Berthold D, Puranik P, Gantar M (2015) Screening of cyanobacteria and microalgae for their ability to synthesize silver nanoparticles with antibacterial activity. Biotechnology Reports 5: $112-119$.

Poguberović SS, Krčmar DM, Maletić SP, Kónya Z, Pilipović DDT, Kerkez DV, Rončević SD (2016) Removal of As (III) and $\mathrm{Cr}$ (VI) from aqueous solutions using "green" zero-valent iron nanoparticles produced by oak, mulberry and cherry leaf extracts. Ecological Engineering 90: 42-49.

Prescott GW (1978) How to know the freshwater algae. Wm. C. Brown Co. Publishers, Iowa.

Raghunandan D, Mahesh BD, Basavaraja S, Balaji SD, Manjunath SY, Venkataraman A (2011) Microwave-assisted rapid extracellular synthesis of stable bio-functionalized silver nanoparticles from guava (Psidium guajava) leaf extract. Journal of Nanoparticle Research 13(5): 2021-2028.

Rajeshkumar S, Kannan C, Annadurai G (2012) Synthesis and characterization of antimicrobial silver nanoparticles using marine brown seaweed Padina tetrastromatica. Drug Invention Today 4(10): 511-513.

Salam MA, Owija NY, Kosa S (2020) Removal of the toxic cadmium ions from aqueous solutions by zero-valent iron nanoparticles. International Journal of Environmental Science and Technology https://doi.org/10.1007/s13762-020-02990-9.

Sandhu RS , Aharwal RP, Kumar S (2019) Green Synthesis: A Novel Approach for Nanoparticles Synthesis. International Journal of Pharmaceutical Sciences and Research 10(8): 3550-3562 DOI: 10.13040/IJPSR.0975-8232.10(8).3550-62.

Sivaprakash A, Aravindhan R, Rao JR, Nair BU (2009) Kinetics and equilibrium studies on the biosorption of hexavalent chromium from aqueous solutions using Bacillus subtilis biomass. Applied Ecology and Environmental Research 7(1): 45-57.

Venkateswarlu S, Kumar SH, Jyothi NVV (2015) Rapid removal of Ni (II) from aqueous solution using 3-Mercaptopropionic acid functionalized bio magnetite nanoparticles. Water Resources and Industry 12: 1-7.

Xu L, Wang YY, Huang J, Chen CY, Wang ZX, Xie H (2020) Silver nanoparticles: Synthesis, medical applications and Biosafety.Theranostics10: 8996-9031. 
Yian Zheng AW (2012) Ag nanoparticle-entrapped hydrogel as promising material for catalytic reduction of organic dyes. Journal of Materials Chemistry 22: 16552-16559.

Yousaf H, Mehmood A, Ahmad KS, Raffi M (2020) Green synthesis of silver nanoparticles and their applications as an alternative antibacterial and antioxidant agents. Materials Science and Engineering 112:

https://doi.org/10.1016/j.msec.2020.110901.

Yousefi N, Jones M, Bismarck A, Mautner A (2021) Fungal chitinglucan nanopapers with heavy metal adsorption properties for ultrafiltration of organic solvents and water. Carbohydrate Polymers 253: 117273

https://doi.org/10.1016/j.carbpol.2020.117273.

Zhang Y, Duan X (2020) Chemical precipitation of heavy metals from wastewater by using the synthetical magnesium hydroxy carbonate. Water Science and Technology 81: 1130-1136.

Zhao Y, Tong T, Wang X, Lin S, Reid EM, Chen Y (2021) Differentiating Solutes with Precise Nanofiltration for Next Generation Environmental Separations: A Review Environmental Science \& Technology 55: 1359-1376. 